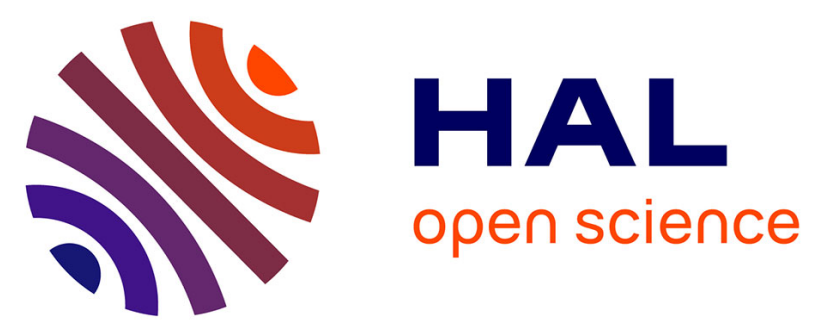

\title{
Reducing Uncertainties of Future Global Soil Carbon Responses to Climate and Land Use Change With Emergent Constraints
}

Wenfang Xu, Jinfeng Chang, Philippe Ciais, Bertrand Guenet, Nicolas Viovy, Akihiko Ito, Christopher Reyer, Hanqing Tian, Hao Shi, Katja Frieler, et al.

\section{To cite this version:}

Wenfang Xu, Jinfeng Chang, Philippe Ciais, Bertrand Guenet, Nicolas Viovy, et al.. Reducing Uncertainties of Future Global Soil Carbon Responses to Climate and Land Use Change With Emergent Constraints. Global Biogeochemical Cycles, 2020, 34 (10), 10.1029/2020GB006589 . hal-02984537

\section{HAL Id: hal-02984537 https://hal.science/hal-02984537}

Submitted on 14 Jun 2021

HAL is a multi-disciplinary open access archive for the deposit and dissemination of scientific research documents, whether they are published or not. The documents may come from teaching and research institutions in France or abroad, or from public or private research centers.
L'archive ouverte pluridisciplinaire HAL, est destinée au dépôt et à la diffusion de documents scientifiques de niveau recherche, publiés ou non, émanant des établissements d'enseignement et de recherche français ou étrangers, des laboratoires publics ou privés. 
Global

\section{Biogeochemical Cycles}

\author{
RESEARCH ARTICLE \\ 10.1029/2020GB006589 \\ Key Points: \\ - The uncertainty in soil organic \\ carbon (SOC) change is dominated \\ by differences between model \\ structure rather than by climate \\ forcing \\ - Soil input changes explain most \\ variations in projected SOC change \\ for natural vegetation across models \\ at global and region \\ - The effective reduction in \\ constrained SOC change depends on \\ climate forcing and region \\ considered
}

Supporting Information:

- Supporting Information S1

Correspondence to:

W. Xu,

xuwenfangfang@163.com

Citation:

Xu, W., Chang, J., Ciais, P., Guenet, B. Viovy, N., Ito, A., et al. (2020). Reducing uncertainties of future global soil carbon responses to climate and land use change with emergent constraints. Global Biogeochemical Cycles, 34, e2020GB006589. https://doi.org/ 10.1029/2020GB006589

Received 24 FEB 2020 Accepted 5 OCT 2020

Accepted article online 15 OCT 2020

(c)2020. American Geophysical Union. All Rights Reserved.

\section{Reducing Uncertainties of Future Global Soil Carbon Responses to Climate and Land Use Change With Emergent Constraints}

\author{
Wenfang Xu1 ${ }^{1}$ (D) Jinfeng Chang ${ }^{1}$ (D), Philippe Ciais ${ }^{1}$ (D), Bertrand Guenet ${ }^{1}$ (D), Nicolas Viovy ${ }^{1}$, \\ Akihiko Ito ${ }^{2}$ (D) Christopher P. O. Reyer ${ }^{3}$ (D) Hanqin Tian $^{4}$ (D), Hao Shi ${ }^{4}$ (D), Katja Frieler ${ }^{3}$ (D), \\ Matthew Forrest $^{5}$ (D), Sebastian Ostberg ${ }^{3}$ (D), Sibyll Schaphoff ${ }^{3}$ (D) and Thomas Hickler ${ }^{5,6}$ iD \\ ${ }^{1}$ Laboratoire des Sciences du Climat et de l'Environnement, IPSL-LSCE, CEA-CNRS-UVSQ, Saclay, France, ${ }^{2}$ National \\ Institute for Environmental Studies, Tsukuba, Japan, ${ }^{3}$ Potsdam Institute for Climate Impact Research (PIK), Member of \\ the Leibniz Association, Potsdam, Germany, ${ }^{4}$ International Center for Climate and Global Change Research, School of \\ Forestry and Wildlife Sciences, Auburn University, Auburn, AL, USA, ${ }^{5}$ Senckenberg Biodiversity and Climate Research \\ Centre (BiK-F), Frankfurt am Main, Germany, ${ }^{6}$ Department of Physical Geography, Goethe University, Frankfurt am \\ Main, Germany
}

\begin{abstract}
Soil organic carbon changes $(\triangle S O C)$ are regulated by climate and land use change. Here, we analyze regional and global $\triangle S O C$ from 1861 to 2099 based on five terrestrial biosphere model (TBM) simulations of the Inter-Sectoral Impact Model Intercomparison Project Phase 2b. The TBMs were driven by harmonized gridded land use change and bias-adjusted climate forcing data from different general circulation models (GCMs) for climate scenarios RCP 2.6 and RCP 6.0. Between 2005 and the end of this century, we estimated an increase of SOC for two scenarios with large uncertainty, which is dominated by differences between TBMs. We present a new emergent constraint approach to constrain future modeled $\triangle S O C$ over natural vegetation from RCP 6.0 simulations using recent observed trends of net primary productivity as a proxy of litter inputs to soil pools. Our results showed that the uncertainties in constrained $\triangle S O C$ can be reduced in comparison with the original model ensemble, but constrained values of $\triangle S O C$ depend on the choice of a GCM and climate regions. For the reduction of the SOC density in areas where cropland expanded ( $\Delta \operatorname{soc}_{\text {cropland expansion }}$ ) over natural vegetation as a result of land use change, the constrained $\Delta s o c_{\text {cropland expansion }}$ still features large uncertainties due to uncertain observed data. Our proposed emergent constraint approach appears to be valuable to reduce uncertainty on SOC projections, but it is limited here by the small number of models (five) and by the uncertainty in the observational data. Applications to larger ensembles from Earth System Models should be tested for the future.
\end{abstract}

\section{Introduction}

Soil organic carbon (SOC) is the largest carbon pool in the terrestrial biosphere, containing 2.3-5.3 times more carbon than the vegetation and the atmosphere (Ciais et al., 2014). Due to its large pool size and gross exchange fluxes representing annually more than $10 \%$ of the mass of carbon in the atmosphere, soil carbon plays a very important role in regulating the global carbon cycle. Soil organic carbon change $(\triangle S O C)$ is controlled by input from plants (litter and exudates), by lateral fluxes (e.g., erosion of particulate organic matter and dissolved organic matter runoff) and by the rate of soil organic matter decomposition (Carvalhais et al., 2014; Todd-Brown et al., 2013; Wu et al., 2018; Yan et al., 2014). These processes are affected by climate and land use change (LUC). LUC over the last century was dominated by the conversion of forests and natural grasslands to cropland and pasture. During this process, SOC inputs are reduced because most of agricultural net primary productivity (NPP) is lower than that of natural systems (Kolby Smith et al., 2014; Neumann \& Smith, 2018) and because only the nonharvested fraction of agricultural NPP is returned to SOC (Haberl et al., 2007; Krausmann et al., 2008). Climate change through temperature and precipitation changes directly modifies both carbon input rates to SOC and decomposition rates. Quantifying and separating the effects of climate change and LUC on SOC change at regional and global scales to improve future $\triangle S O C$ projections is a key research challenge, which has implications for mitigation solutions based on increasing soil organic matter stocks in soils. 
Observational data are valuable to quantify the global spatial distribution of SOC (Harmonized World Soil Database [HWSD], FAO/IIASA/ISRIC/ISSCAS/JRC, 2012; the Northern Circumpolar Soil Carbon Database [NCSCD], Tarnocai et al., 2009; the World Inventory of Soil Emission Potentials [WISE30sec], Batjes, 2016; the Unified North American Soil Map [UNASM], Liu et al., 2013; and the SoilsGrids250 database, Hengl et al., 2017). For evaluating historical changes of SOC, there are only few sites where long-term measurements are available, especially for natural ecosystems. Meta-analysis of SOC changes after LUC were reported by previous studies (Guo \& Gifford, 2002; Li et al., 2017, 2018; Post \& Kwon, 2000). Observed regional changes of SOC from inventories are reported by some studies (Bellamy et al., 2005; Doetterl et al., 2015; Hamdi et al., 2013).

Modeled estimates of global and regional SOC changes during the historical period have been reported by terrestrial biosphere models (TBMs; e.g., Tian et al., 2015) and in some cased data-driven models, for example, Sanderman et al. (2017) for grasslands SOC losses due to past land use. For future projections, estimations of SOC changes are based on TBMs coupled with general circulation models (GCMs) or run offline with climate forcing from GCM simulations. Projections of SOC from coupled models are particularly uncertain (Koven et al., 2015; Luo et al., 2016; Nishina et al., 2014; Todd-Brown et al., 2014), partly because models are not well calibrated and evaluated against observed data (Luo et al., 2016; Xiao et al., 2014) and partly because carbon cycle coupled models have climate biases. Global SOC stocks were found to vary from 510 to 3,040 Pg C in the period 1995-2005 among 11 models of the Coupled Model Intercomparison Project 5 (CMIP5) (Todd-Brown et al., 2013). This large range was attributed to differences in model structure, parameter values, and climate input fields. To better understand the different sources of model uncertainties, model-to-model variation in $\triangle S O C$ was decomposed into uncertainties due to initial SOC stocks (the SOC stocks during 1997-2006), relative changes in soil inputs, and decomposition rates/turnover times following ideas proposed by Koven et al. (2015) and Todd-Brown et al. (2014).

Compared to ensembles of SOC simulations from fully coupled GCMs that differ in their climate, ensembles of SOC simulations from offline TBMs forced by bias-adjusted climate forcing data allow us to focus on structural errors of TBMs. Over the historical period (i.e., 2010) during which climate forcing can be obtained from observations to drive TBMs, Tian, Lu, et al. (2015) analyzed SOC from 10 models of the Multi-scale Synthesis and Terrestrial Model Intercomparison Project (MsTMIP). They found that (i) the magnitude of SOC stocks ranged from 425 to 2,111 Pg C across models, slightly narrower the range (510-3,040 Pg C during 1995-2005) of TBMs reported by Todd-Brown et al. (2013), and (ii) cumulative SOC changes during the historical period differed from -70 to $86 \mathrm{Pg} \mathrm{C}$. This large spread suggests that model structural errors are dominant in both initial SOC stock and SOC changes simulations. Up to now, no study has linked systematic errors of modeled SOC change errors between the historical period and future projections.

The emergent constraint approach allows using historical simulations and observed data to reduce uncertainty in future projections of earth system variables (Hall et al., 2019). This approach relies on the assumption that historical or present-day differences between models and observed data are preserved in future projections and reflect stationary differences explained by models' structure. Thus, if we can estimate an effective emergent constraint using contemporary observations, it helps to downweigh less realistic models and reduce the spread of the ensemble. This approach was applied to constrain for instance snow albedo temperature sensitivities (Hall et al., 2019), tropical carbon cycle sensitivity to warming (Cox et al., 2013), global ratio of plant transpiration to total terrestrial evapotranspiration (Lian et al., 2018), future yield changes (Zhao et al., 2016), and $\mathrm{CO}_{2}$ fertilization of land photosynthesis (Wenzel et al., 2016). Such an approach was also applied to reduce the uncertainty in projections of permissible emissions for climate stabilization (Jones et al., 2005). In this study, we attempt to apply a new emergent constraint approach to reduce uncertainties related to future SOC changes $(\triangle S O C)$ by an ensemble of offline terrestrial carbon cycle models, hereafter called TBMs. Specifically, we aim to

1. Compare $\triangle S O C$ in past and future from five different ISIMIP2b TBMs (LPJ-GUESS, LPJmL, VISIT, ORCHIDEE-MICT, and DLEM) forced by the same set of bias-adjusted climate forcing from different climate models under two different greenhouse gas concentration pathways (RCP 2.6 and RCP 6.0) and corresponding land use scenarios. 
2. Quantify the contributions of initial soil carbon, changes in decomposition rate, and changes in soil inputs to the model spread of $\triangle S O C$ in natural ecosystems, that is, ecosystems where the climate and $\mathrm{CO}_{2}$ perturbation dominate $\mathrm{SOC}$ changes.

3. Reduce the model spread of $\triangle S O C$ in natural ecosystems caused by climate and $\mathrm{CO}_{2}$-driven soil carbon inputs changes, using observed input changes approximated by NPP trends, with an emergent constraint approach.

4. Reduce the model spread of $\triangle S O C$ in ecosystems where land use conversion of natural ecosystems to croplands has been driving SOC, using observations of SOC densities changes before and after land use, with an emergent constraint approach.

\section{Methods}

\subsection{ISIMIP2b Biome Models and Simulation Setup}

The Inter-Sectoral Impact Model Intercomparison Project Phase 2b (ISIMIP2b) provides simulations of TBMs driven with several bias-adjusted climate fields and LUC scenarios for the period from 1861 to 2099 (Frieler et al., 2017). The ISIMIP2b models were driven by gridded, daily bias-adjusted climate from different CMIP5 GCMs (Frieler et al., 2017; Lange, 2016), global annual atmospheric $\mathrm{CO}_{2}$ concentration, and harmonized annual land use maps (Klein Goldewijk et al., 2017). Models performed a spin-up to simulate land carbon pools in 1860 as described in the protocol (https://www.isimip.org/protocol/\#isimip2b). The use of bias-adjusted climate data ensures that TBMs are forced by climate that match observations in the last 40 years of the historical period and that there is no discontinuity of climate forcing between the past and the future. Note however that decadal and interannual variations of the ISIMIP2b climate forcing do not match observed climate variability since variability follows the one of each GCM. Decadal and interannual climate variability as well as historical climate trends thus differ between bias-adjusted GCMs. The key point is that the use of common bias-adjusted climate forcing for the historical period and the future in this study reduces the spread in SOC projections from TBMs compared to using TBMs fully coupled with climate models that have considerable climate differences. This makes it possible for us to focus on structural uncertainties from TBMs and yet to examine the impact of different GCMs and scenarios for the future.

Five TBMs from the ISIMIP2b biome sector were used (supporting information Table S1): LPJ-GUESS (Smith et al., 2014), LPJmL (Bondeau et al., 2007), VISIT (Ito \& Inatomi, 2012), DLEM (Tian et al., 2015), and ORCHIDEE-MICT (Guimberteau et al., 2018). These models differ in their biogeochemical parameterizations and thus in their simulated response of SOC to climate and LUC (Table S1), but they nevertheless share the same philosophy for their soil carbon modules using first-order kinetics equations applied to one to three pools adjusted by soil temperature and moisture. SOC stock at soil depth of $0-1 \mathrm{~m}$ was calculated from carbon mass in soil pool (litter was not included) based on ISIMIP2b simulations. All models simulated carbon cycling in terrestrial ecosystem with different discretization of vegetation into plant functional types (PFTs). Three models (ORCHIDEE-MICT, LPJmL, and DLEM) include permafrost. None of the models includes wetlands (Table S1). We selected TBM output from simulations driven by bias-adjusted daily climate forcing of four different GCMs: GFDL-ESM2M, HadGEM2-ES, IPSL-CM5A-LR, and MIROC5 (Frieler et al., 2017) at a spatial resolution of $0.5 \times 0.5^{\circ}$ for the RCP 2.6 and RCP 6.0. An exception is ORCHIDEE-MICT, which used climate forcing at a resolution of $1.0 \times 1.0^{\circ}$, and its results were downscaled to $0.5 \times 0.5^{\circ}$.

Historical LUC forcing for ISIMIP2b was derived from the LUH2 gridded reconstruction based on HYDE3.2 data (Klein Goldewijk et al., 2017). The LUH2 data were further disaggregated into annual land use maps with major crop types, rainfed, and irrigated (Monfreda et al., 2008) for ISIMIP2b. Future LUC forcing was based on projections from the MAgPIE land use model (Popp et al., 2014; Stevanović et al., 2016) assuming population growth and economic development following the SSP2 storyline (Popp et al., 2017) and including climate change impacts on crop yields estimated by the LPJmL crop model (Müller \& Robertson, 2014) for each RCP scenario (Frieler et al., 2017). To ensure continuity of spatially explicit LUC forcing from historical to future period, the LUH2 harmonization method was applied (Frieler et al., 2017). In addition to anthropogenic LUC, LPJmL and LPJ-GUESS activated a dynamic vegetation module across historical and future periods to simulate changes of natural vegetation in response to climate and $\mathrm{CO}_{2}$. ORCHIDEE-MICT used the reconstructed land cover maps (with historical LUC from LUH2) for 
Table 1

Description of Scenario Design Used From ISIMIP2b

\begin{tabular}{llll}
\hline ISIMIP2b simulations & \multicolumn{1}{c}{ Driver } & Description \\
\hline Group 1 & Historical (1861-2005) & Climate + land use & $\begin{array}{c}\text { The effects of historical climate change with varying } \\
\text { land use change } \\
\text { Group 2 }\end{array}$ \\
Only CC (2006-2099) & Climate + fixed land use & $\begin{array}{c}\text { Pure of future climate change assuming fixed year 2005 levels } \\
\text { of land use change under RCP 2.6 and 6.0 scenarios } \\
\text { The effects of future climate change and land use change from 2005 onwards } \\
\text { associated with RCP 2.6 and 6.0 scenarios }\end{array}$ \\
Group 3 & CC + LUC (2006-2099) & Climate + land use & Pure effect of future land use change under RCP 2.6 and 6.0 scenarios \\
\hline
\end{tabular}

Note. You can find different climate and land use change impact simulation data (the simulation round, sectors, scenarios, variables, time period, etc.) online (https://esg.pik-potsdam.de/projects/isimip/).

the period 1860-2005 (Peng et al., 2017), and the trend of natural vegetation dynamics (prescribed from a run of ORCHIDEE-MICT with activated dynamic vegetation module) for the period 2006-2099, so that it simulated natural vegetation changes for the future. VISIT and DLEM assumed static natural vegetation by prescribing natural vegetation maps for 1860-2099.

Variable agricultural area (cropland and pasture) from LUH2 was used as input to TBMs. Each model started from the same 1860 agricultural area from LUH2 and nonharmonized preindustrial natural vegetation distributions and used different transition rules for converting a fraction of natural vegetation to LUH2 agriculture land (or vice versa) in each grid cell, each year. The models did not report SOC for each PFT in each grid cell, which would have allowed a precise evaluation of SOC changes in all agricultural PFTs, that is, cropland land use type, versus all natural PFTs, separately. To overcome this limitation, we calculated " $\triangle S O C$ from cropland-dominated areas" by selecting only grid cells where the cropland fraction is larger than $30 \%$ in 2005 (Figure S1).

Three groups of simulations defined by the ISIMIP2b protocol were analyzed (Frieler et al., 2017; Table 1). Group 1 contains simulations driven by historical climate and LUC during 1861-2005. Group 2 contains simulations driven by future climate change with a fixed future land use map equal to that of year 2005 . Group 2 simulations are thus driven only by climate change and named after CC. Group 3 contains simulations driven by both future climate and LUC (hereafter, CC + LUC). The difference of SOC between Group 2 and Group 3 simulations gives the effect of future LUC assuming drivers are additive.

We separated the analysis of $\triangle S O C$ between grid cells dominated by cropland (cropland fraction more than $30 \%$ in 2005) and grid cells with no or little cropland (cropland fraction less than $30 \%$ in 2005), defined as "natural vegetation," although it is an approximation since those grids still have SOC from croplands; $54.3 \%$ of these natural vegetation grids cells still include small cropland fractions (83.7\% out of the $54.3 \%$ have a cropland fraction lower than $15.0 \%$; Figure S1f). Grid cells dominated by historical cropland summed up to $10.0 \%$ of the global land grid cells (Figure S1f). For each of these two categories, a separate approach is used to constrain $\triangle S O C$ with different types of observations.

\subsection{Constraining $\triangle S O C$ in Areas Dominated by Cropland}

Bookkeeping land use models, data-driven models, and TBMs indicate that agricultural expansion caused a net soil carbon loss in the past (Hansis et al., 2015; Houghton \& Nassikas, 2017; Li et al., 2017; Sanderman et al., 2017). Generally, after conversion to cropland, there is a SOC loss during the first years because cultivated land has a lower NPP than natural ecosystems (Kolby Smith et al., 2014; Neumann \& Smith, 2018) and because agricultural NPP is harvested and tillage accelerates SOC decomposition.

To constrain historical $\triangle S O C$ from cropland-dominated grid cells (Figure 1a) by observations, we hypothesized that there is a strong relationship between (i) $\triangle S O C$ per unit area over the grid cells dominated by historical cropland expansion ( $\triangle S S_{\text {cropland expansion, }}$ calculated as $\triangle S O C$ divided by the increased area of cropland, the notations without capital letters meaning SOC per unit area) and (ii) the difference of SOC per unit area between cropland and initial natural vegetation ( $\left.\Delta s c_{\text {cropland minus initial natveg }}\right)$. For example, in the case of a grid cell that was $100 \%$ covered by natural vegetation in 1861 and is now $100 \%$ covered by cropland, $\Delta s c_{\text {cropland expansion }}$ is strictly equal to $\Delta s c_{\text {cropland minus initial natveg. }}$. The idea is that $\Delta s o c_{\text {cropland }}$ 
(a) Constraining $\triangle \mathrm{SOC}$ in areas dominated by land use

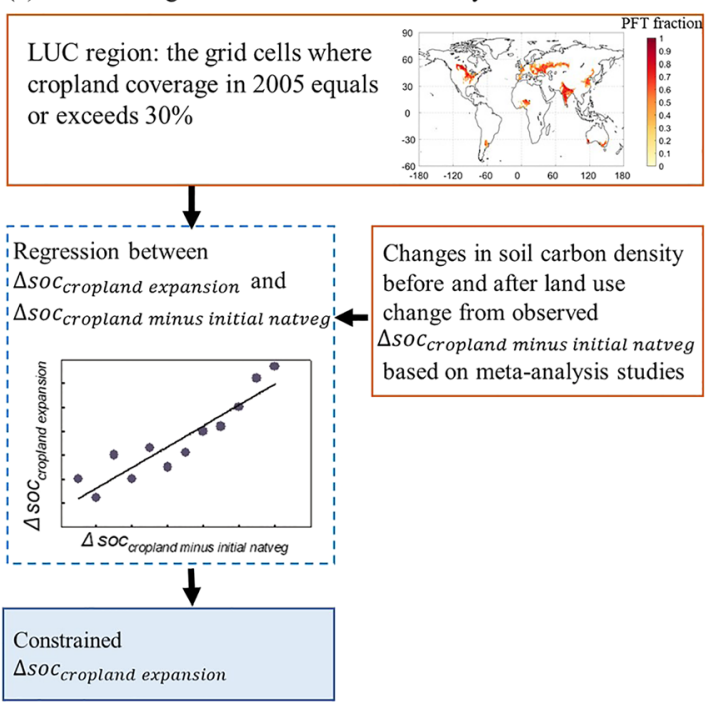

(b) Constraining $\triangle \mathrm{SOC}$ in areas dominated by climate change

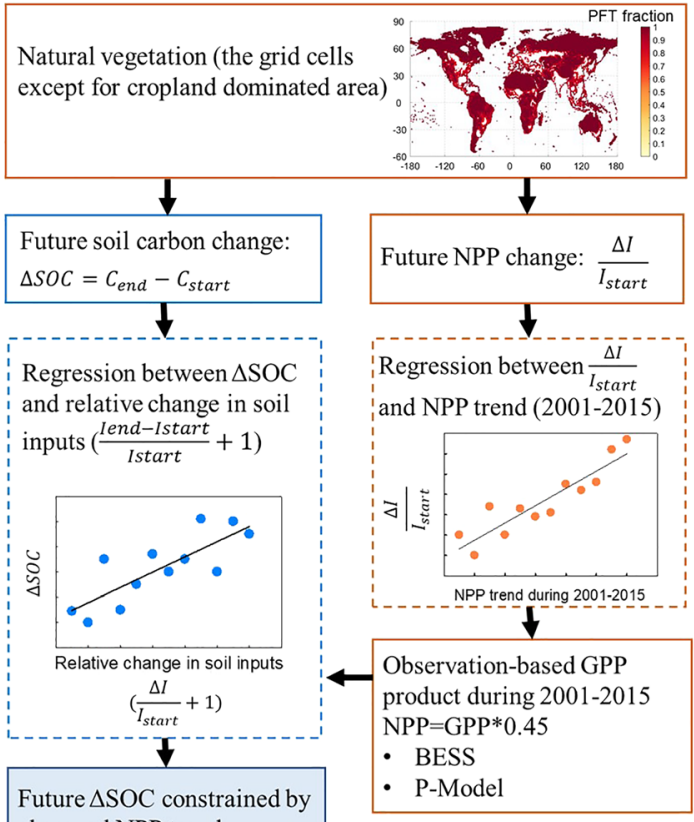

observed NPP trend

Figure 1. The framework of emergent constraint approach in areas dominated by land use change (a) and areas dominated by climate change (b).

minus initial natveg can be obtained from observations of SOC density across different land use types in the same

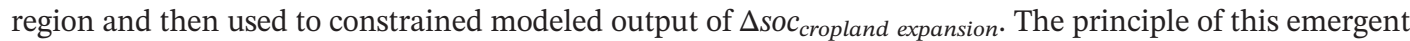
constraint is illustrated in Figure 1a. It should be noted that the $\Delta s s_{\text {cropland minus initial natveg will be affected }}$ by transient climate, especially by transient $\mathrm{CO}_{2}$, which would lead to biases estimates of $\triangle S O C$.

To verify the above hypothesis, we established regional regressions between $\Delta s_{\text {cocopland expansion }}$ and

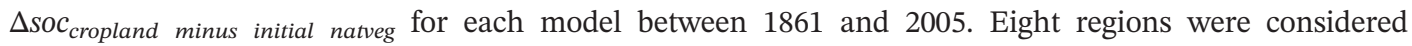
(Eurasia, North America, South America, West Eurasia, Australia, South Asia, and East Asia; Figures S1c

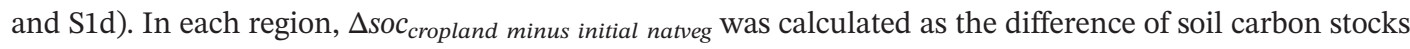
densities of grid cells dominated by cropland grid cells with a cropland fraction larger than 50\% in 2005 and grid cells with a natural vegetation fraction higher than $50 \%$ in 1861 in each region of Figures $1 \mathrm{c}$ and 1d, based on historical simulations (Group 1). The choice of a $50 \%$ fraction threshold was made by considering the trade-off between a strong relationship between $\Delta s o c_{\text {cropland expansion }}$ and $\Delta s c_{c}$ cropland minus initial natveg (Figure S2) and a sufficient number of dominated cropland grids number (Figure S1e). The results of these regressions confirmed that $\Delta S O c_{\text {cropland expansion }}$ and $\Delta S O c_{\text {cropland minus initial natveg }}$ are indeed strongly positively correlated across different TBMs (see in section 3.3.3). Thus, it is justified to constrain modeled

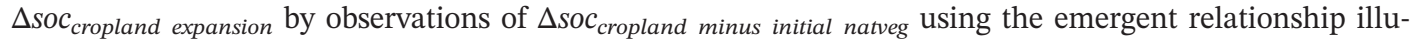
strated in Figure 1a. We compiled field observations of the SOC density (Deng et al., 2016; Li et al., 2018; Nyawira et al., 2016), hereafter referred to as soc, for natural vegetation and cropland in each region, and

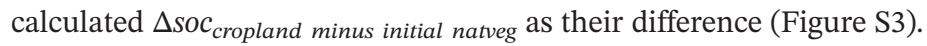

During the selection of field soc data, two criteria were considered: (1) studies must report cropland soc measurements and (2) soc measurements must come from paired adjacent sites, one with natural vegetation type and the other with cropland. Overall, 274 paired data were selected from 147 study sites (Figure S1c) to assess

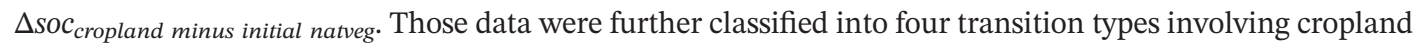
in different climate regions, including forest to cropland transitions in tropical region (F-C, Trop; $n=78$ ), forest to cropland transitions in temperate region (F-C, Temp; $n=49$ ), grassland to cropland in tropical region (G-C, Trop; $n=15)$, and grassland to cropland in temperate region (G-C, Temp; $n=132)$. In order

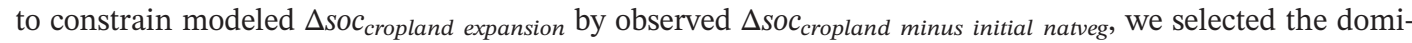
nant type of transition to croplands in each region from the models (Figures S1b-S1d and Table 5) and 


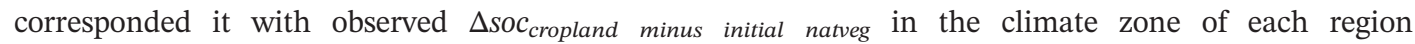
(Figures S1b-S1d).

\subsection{Constraining $\triangle S O C$ in Areas of Natural Vegetation Where SOC Change Is Dominated by Climate Change}

In grid cells dominantly covered by natural vegetation with a cropland fraction less than $30 \%$ in 2005 , we assumed that $\triangle S O C$ can be mainly explained by climate- and $\mathrm{CO}_{2}$-induced shifts in the balance between litter input and decomposition rates (Todd-Brown et al., 2013). Todd-Brown et al. (2014) showed that model-to-model variation in $\triangle S O C$ across the CMIP5 models could be explained $\left(R^{2}=0.89, p<0.01\right)$ by differences in initial soil carbon stocks combined with relative changes in soil inputs and decomposition rates. We used the same attribution method to quantify the impact of the three key variables on $\triangle S O C$ from ISIMIP2b models, based on Group 2 simulations (CC). Todd-Brown et al. (2014) assumed that $\triangle S O C$ from transient ESM model runs is equal to the difference of their equilibrium SOC pools between the end and the start of each run, so that $\triangle S O C$ can be written as

$$
\Delta S O C=C_{\text {end }}-C_{\text {start }}=\frac{I_{\text {end }}}{k_{\text {end }}}-\frac{I_{\text {start }}}{k_{\text {start }}},
$$

where $I$ is the soil carbon input approximated by NPP; $k$ is the decomposition rate and calculated from global heterotrophic respiration divided by soil carbon stocks; and subscripts end and start are for the initial and final state of a simulation. Here we consider the period of 2040-2049 for RCP 2.6 and 2090-2099 for RCP 6.0 as the final state and the period of 1995-2005 as the initial state. The choice of 2040-2049 as the final state for RCP 2.6 is because in this scenario, atmospheric $\mathrm{CO}_{2}$ concentration that drives the positive trend of NPP and soil $\mathrm{C}$ inputs through the $\mathrm{CO}_{2}$ fertilization effect present in all TBMs peaks by 2050s and decreases thereafter (Meinshausen et al., 2011). After that date, decreasing $\mathrm{CO}_{2}$ may cause a decrease of NPP and soil $\mathrm{C}$ input, inducing a decrease of SOC with a time delay, which complicates the use of Equation 1. Equation 1 can be rearranged into

$$
\Delta S O C=C_{\text {end }}-C_{\text {start }}=\left(\frac{1+\frac{\Delta I}{I_{\text {start }}}}{1+\frac{\Delta k}{k_{\text {start }}}}-1\right) \times C_{\text {start }} .
$$

Using regression analysis of modeled $\triangle S O C$ with the terms on the right-hand side of Equation 2, we assessed the relative contributions of changes in soil inputs $\left(1+\frac{\Delta I}{I_{\text {start }}}\right)$, changes in decomposition rate $\left(1+\frac{\Delta k}{k_{\text {start }}}\right)$, and initial soil carbon stocks $\left(C_{\text {start }}\right)$ to the modeled $\triangle S O C$. The regression is executed across different TBMs for each GCM (i.e., one regression for each GCM) averaging all variables over grid cells with natural vegetation.

Because $\Delta I$ is the difference between NPP in the future and historical period, we could not derive the $\Delta I$ from observed NPP data sets. As a result, we used two-step emergent constraint method to constraint future $\triangle S O C$, that is, constrain future minus present $\Delta I$ from the current derivative of NPP in the past 15 years (Figure 1b). The first step is to constrain future $\frac{\Delta I}{I_{\text {start }}}$ from past NPP trends, if there is a strong enough linear relationship between these two variables across TBMs. To test for such a relationship, we established linear regressions between future $\frac{\Delta I}{I_{\text {start }}}$ and past NPP trends during 2001-2015 from the different models, and then we used the observed NPP trends to constrain $\frac{\Delta I}{I_{\text {start }}}$. In the second step, we established linear regressions between future $\triangle S O C$ and $1+\frac{\Delta I}{I_{\text {start }}}$ from models from Equation 2 and then used the constrained future $\frac{\Delta I}{I_{\text {start }}}$ from the first step to constrain future $\triangle S O C$. This strategy is summarized in Figure 1b. We constrain $\triangle S O C$ for global natural vegetation and each climate region using the same emergent constraint than above. 
The hypothesis behind this two-step emergent constraint is that future carbon input changes can be constrained from observation-based trends of past NPP. The trends of observed NPP were derived from trends of observation-based photosynthesis (GPP) from gridded data sets assuming a constant ratio of NPP to GPP equal to 0.45 (He et al., 2018). GPP trends were estimated from two data-driven models that include both the effect of rising $\mathrm{CO}_{2}$ on photosynthesis and satellite-observed trends of leaf area (Jiang \& Ryu, 2016; Wang et al., 2017). Note that we did not to use trends of satellite based NPP models based on AVHRR greenness data and light-use efficiency (LUE) models (Kolby Smith et al., 2015) and on MODIS (Zhao \& Running, 2010) because their LUE formulation ignores the fertilization effect of increasing $\mathrm{CO}_{2}$ and thus likely underestimates NPP trends in this approach (De Kauwe et al., 2016).

The two GPP data-driven models are the P model (Stocker et al., 2019; Wang et al., 2017) and the Breathing Earth System Simulator (BESS) model simulations (Jiang \& Ryu, 2016; Ryu et al., 2011) during the period of 2001-2015. The P model is an LUE model in which LUE depends on environmental condition (air temperature, vapor pressure deficit, and elevation) and $\mathrm{CO}_{2}$ concentrations, with an optimality principle that predicts stomatal conductance and foliar photosynthetic traits based on a standard model for C3 leaf photosynthesis. The bias of the P model for global GPP is 3.81\% (Wang et al., 2017). BESS is a process-based GPP model that uses remotely sensed data of land surface and air temperature, leaf area index ( $\mathrm{LAI}), \mathrm{CO}_{2}$ concentrations, and canopy information. The bias of BESS for global GPP is 1.92\% (Jiang \& Ryu, 2016). Significant increase in NPP is produced by those two data-driven approaches. Models in natural ecosystem during the period of 2001-2015, with a trend of $0.11 \mathrm{Pg} \mathrm{C} \mathrm{yr}^{-2}$ in BESS and a trend of $0.21 \mathrm{Pg} \mathrm{C} \mathrm{yr}^{-2}$ in P model. Larger increase in NPP was found in P model for tropical, temperate, and boreal regions (Table S2).

In the two-step emergent constraint approach illustrated in Figure 1b, uncertainties in constrained $\triangle S O C$ are a function of uncertainties in litter carbon input trend constrained by the observed trend of NPP, and in the linear regression slopes of regressions between $\frac{\Delta I}{I_{\text {start }}}$ and past input changes, and between $\triangle S O C$ and $\left(1+\frac{\Delta I}{I_{\text {start }}}\right)$ are considered. The uncertainty in constrained $\triangle S O C$ is calculated as in Stegehuis et al. (2013) by

$$
\begin{gathered}
\sigma_{\Delta S O C}=\sqrt{\frac{\beta^{2} \sigma^{2} \frac{\Delta I}{I_{\text {start }}}+\sigma_{\text {res_ } \triangle S O C}^{2}}{\sigma_{\text {start }}}}, \\
\sigma_{\Delta I}=\sqrt{\alpha^{2} \sigma_{o b s}^{2}+\sigma_{\text {res_obs }}^{2}},
\end{gathered}
$$

where $\sigma \Delta S O C, \sigma_{\frac{\Delta I}{I_{\text {start }}}}$, and $\sigma_{o b s}$ are the uncertainties in constrained $\Delta S O C$, the uncertainties in $\frac{\Delta I}{I_{\text {start }}}$, and uncertainties in the past NPP trend based on two data sets. $\beta$ and $\sigma_{\text {res__SOC }}$ indicate the slope and standard deviation of the residuals from linear regression between $\Delta S O C$ and $1+\frac{\Delta I}{I_{\text {start }}}$. Similarly, $\alpha$ and $\sigma_{\text {res_obs }}$ present the linear regression between $\frac{\Delta I}{I_{\text {start }}}$ and past NPP trend.

Last, in the attribution of $\triangle S O C$ differences for natural vegetation between models given by Equation 2, the term related to initial SOC stocks differences across models can also be constrained from observations. Three global SOC data sets were used for this purpose, the HWSD (FAO/IIASA/ISRIC/ISSCAS/JRC, 2012), the NCSCD (Tarnocai et al., 2009), and the WISE30sec (Batjes, 2016).

\section{Results}

\subsection{Changes in the Modeled Global Soil Carbon}

We found large differences in simulated global $\triangle S O C$ for the historical period (1861-2005; Group 1 simulations), ranging from $-81.3 \mathrm{Pg} \mathrm{C}$ (LPJmL driven by IPSL-CM5-LR climate) to $88.8 \mathrm{Pg} \mathrm{C}$ (VISIT driven by HadGEM2-ES climate; Figure 2 and Table 2). For the future period of 2006-2099 in Group 2 simulations with CC + LUC effects, model differences of global $\triangle S O C$ are also large, going from $-9.4 \mathrm{Pg}$ C (LPJmL 
(a) CC+LUC RCP2.6

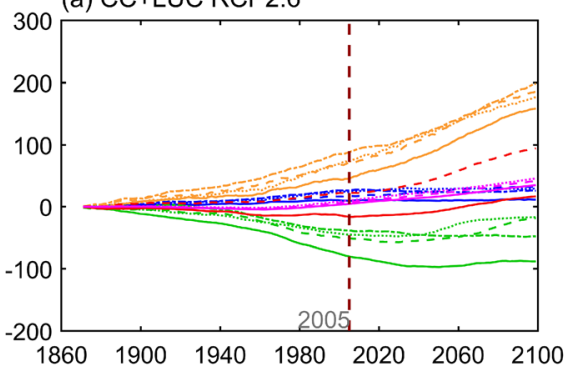

(c) Only CC RCP2.6

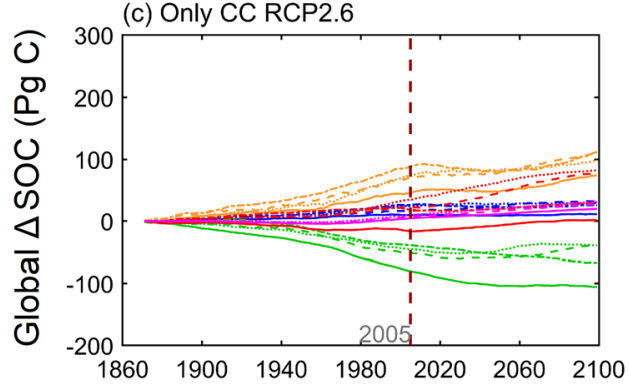

(e) Only LUC RCP2.6

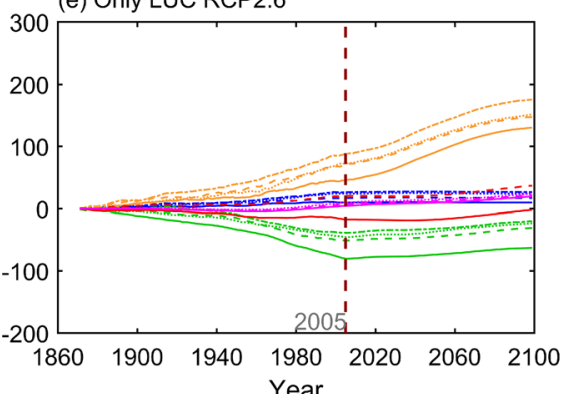

Model name —LPJ-GUESS — LPJmL — VISIT — ORCHIDEE-MICT — DLEM

Climate forcing - - GFDL-ESM2M ---- HadGEM2-ES — IPSL-CM5A-LR …… MIROC5 (b) CC+LUC RCP6.0

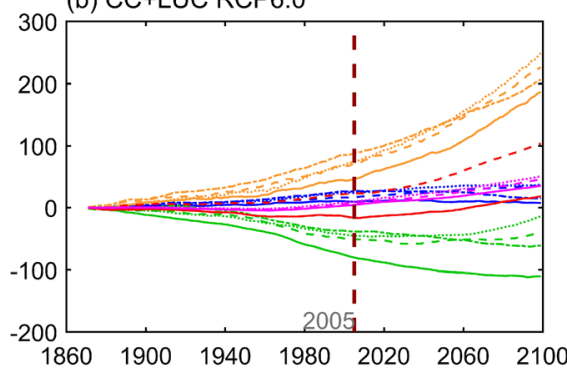

(d) Only CC RCP6.0

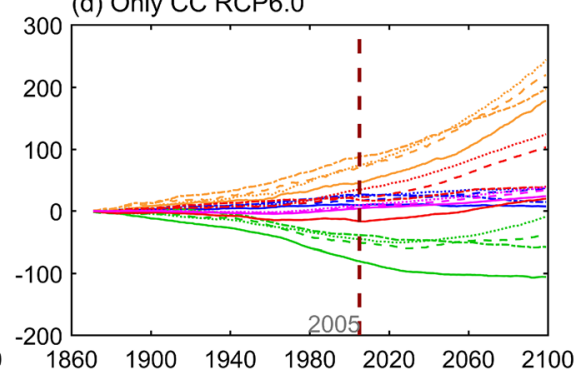

(f) Only LUC RCP6.0

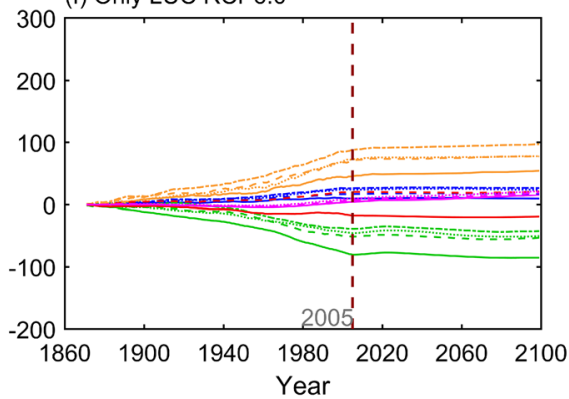

Figure 2. Changes of global soil organic carbon $(\triangle S O C)$ compared to the historical (1861-1870) under both the effects of climate change and land use change (CC + LUC), the effect of climate change (only CC), and the effect of land use change (only LUC) based on RCP 2.6 and 6.0 during the period of 1871-2099.

driven by HadGEM2-ES climate forcing) to 114.7 Pg C (VISIT driven by GFDL-ESM2M climate) for RCP 2.6 and from -30.1 Pg C (LPJmL driven by IPSL-CM5-LR climate) to 176.5 Pg C (VISIT driven by MIROC5 climate) for RCP 6.0 (Figure 2 and Table 2).

The interquartile range (IQR, the difference between 75 th and 25th percentile of the data) of future $\triangle S O C$ across all GCMs forcing data and TBMs is larger for RCP 6.0 (81.9 Pg C) than that for RCP 2.6 (73.9 Pg C; Figure $3 \mathrm{a}$ and Table S3). The larger IQR of $\triangle S O C$ for RCP 6.0 is partly explained by diverging model responses to climate change alone, with an IQR of $69.6 \mathrm{Pg} \mathrm{C}$ from the effects of climate change alone in RCP 6.0 compared to a climate change induced IQR of $19.9 \mathrm{Pg} \mathrm{C}$ in RCP 2.6 (Figure 3b and Table S3). The difference in IQR of $\triangle S O C$ between RCP $6.0(\mathrm{IQR}=14.2)$ and $\mathrm{RCP} 2.6(\mathrm{IQR}=25.5)$ was reduced when considering the effects of LUC alone, even though a larger IQR was found in RCP 2.6. The IQR of $\triangle S O C$ caused by different GCMs forcing, obtained by averaging all TBMs outputs for the same GCM, is smaller than the IQR across TBMs, with an IQR across GCMs of $15.2 \mathrm{Pg} \mathrm{C}$ in RCP 2.6 and $30.6 \mathrm{Pg} \mathrm{C}$ in RCP 6.0 (Figure 3a). The spread of $\triangle S O C$ is thus mainly due to structural differences in TBMs, with an IQR of 56.8 Pg C across TBMs for RCP 2.6 and 73.7 Pg C for RCP 6.0 (fourth column of Figure 3a). The relative shares of both GCM versus TBM-related uncertainties are similar for both scenarios (Figures 3a-3c).

Under effects of CC + LUC, the change of SOC during 2006-2099 is a net increase of $41.8 \pm 43.9$ Pg C $(3.2 \pm 3.4 \%)$ for RCP 2.6 and of $48.5 \pm 63.3 \mathrm{Pg} \mathrm{C}(3.8 \pm 4.8 \%)$ for RCP 6.0 across all TBMs and GCMs 
Table 2

Modeled Global Soil Carbon Changes ( $\triangle S O C$ ) During Historical Period (1861-2005) and During Future Period (2006-2099) Under Both the Effects of Climate Change and Land Use Change (CC + LUC), the Effect of Only Climate Change (CC), and the Effect of Only Land Use Change (LUC) Based on RCP 2.6 and 6.0

\begin{tabular}{|c|c|c|c|c|c|c|c|c|}
\hline \multirow{3}{*}{$\begin{array}{l}\triangle S O C(\operatorname{Pg~C}) \\
\text { TBMs }\end{array}$} & \multirow[b]{3}{*}{ GCM } & \multirow{3}{*}{$\begin{array}{c}\text { History } \\
2005-1861\end{array}$} & \multicolumn{6}{|c|}{ Future (2099-2005) } \\
\hline & & & \multicolumn{3}{|c|}{ RCP 2.6} & \multicolumn{3}{|c|}{ RCP 6.0} \\
\hline & & & $\mathrm{CC}+\mathrm{LUC}$ & $\mathrm{CC}$ & LUC & $\mathrm{CC}+\mathrm{LUC}$ & $\mathrm{CC}$ & LUC \\
\hline \multirow[t]{4}{*}{ LPJ-GUESS } & GFDL-ESM2M & 16.5 & 14.9 & 15.1 & -0.2 & 18.3 & 18.4 & -0.1 \\
\hline & HadGEM2-ES & 26.0 & -0.5 & -0.6 & 0.1 & -11.3 & -11.4 & 0.1 \\
\hline & IPSL-CM5A-LR & 9.3 & 1.9 & 1.8 & 0.1 & -1.9 & -1.8 & -0.1 \\
\hline & MIROC5 & 23.4 & 5.6 & 5.8 & -0.2 & 13.2 & 13.4 & -0.2 \\
\hline \multirow[t]{4}{*}{ LPJmL } & GFDL-ESM2M & -52.1 & 31.9 & 11.7 & 20.2 & 10.0 & 12.1 & -2.1 \\
\hline & HadGEM2-ES & -38.6 & -9.4 & -28.2 & 18.8 & -22.9 & -19.4 & -3.5 \\
\hline & IPSL-CM5A-LR & -81.3 & -8.0 & -25.5 & 17.4 & -30.1 & -25.3 & -4.8 \\
\hline & MIROC5 & -45.0 & 28.0 & 5.9 & 22.1 & 31.4 & 36.3 & -4.9 \\
\hline \multirow[t]{4}{*}{ VISIT } & GFDL-ESM2M & 71.4 & 114.7 & 38.5 & 76.3 & 154.9 & 148.9 & 6.0 \\
\hline & HadGEM2-ES & 88.8 & 109.9 & 22.8 & 87.1 & 118.4 & 109.4 & 8.9 \\
\hline & IPSL-CM5A-LR & 46.1 & 112.7 & 28.4 & 84.3 & 141.0 & 132.5 & 8.5 \\
\hline & MIROC5 & 72.5 & 103.9 & 25.5 & 78.4 & 176.5 & 171.5 & 5.0 \\
\hline \multirow{4}{*}{ ORCHIDEE-MICT } & GFDL-ESM2M & 22.6 & 71.7 & 55.1 & 16.6 & 80.9 & 80.6 & 0.3 \\
\hline & HadGEM2-ES & 18.0 & - & 11.3 & - & - & 21.4 & - \\
\hline & IPSL-CM5A-LR & -17.4 & 33.3 & 17.9 & 15.4 & 35.0 & 36.9 & -1.9 \\
\hline & MIROC5 & 34.2 & - & 47.8 & - & - & 89.9 & - \\
\hline \multirow[t]{3}{*}{ DLEM } & GFDL-ESM2M & 7.2 & 34.5 & 20.1 & 14.4 & 38.6 & 26.8 & 11.8 \\
\hline & IPSL-CM5A-LR & 4.3 & 30.3 & 15.2 & 15.0 & 30.8 & 19.7 & 11.0 \\
\hline & MIROC5 & 9.7 & 36.0 & 21.8 & 14.2 & 40.9 & 29.2 & 11.7 \\
\hline Model range & & -81.3 to 88.8 & -9.4 to 114.7 & -28.2 to 55.1 & -0.2 to 87.1 & -30.1 to 176.5 & -25.3 to 171.5 & -4.9 to 11.8 \\
\hline Model mean & & 11.4 & 41.8 & 15.3 & 28.2 & 48.5 & 46.8 & 2.7 \\
\hline Model median & & 16.51 & 31.91 & 15.22 & 16.61 & 31.40 & 26.83 & 0.14 \\
\hline
\end{tabular}

Note. The bold and bold-italic indicate the largest and smallest values, respectively. The $\triangle S O C$ is the difference in SOC compared to the means of $1861-1870$.

(Figure 2 and Table 2). Climate change alone caused larger SOC changes of $46.8 \pm 58.2 \mathrm{Pg} \mathrm{C}(3.4 \pm 4.3 \%)$ under RCP 6.0 than $15.3 \pm 20.8 \mathrm{Pg} \mathrm{C}(1.2 \pm 1.3 \%)$ under RCP 2.6 (Table 2). In addition, LUC alone after 2005 caused a SOC increase of $28.2 \pm 31.4 \mathrm{Pg}$ C under RCP 2.6 and $2.7 \pm 5.9 \mathrm{Pg}$ C under RCP 6.0. The LUC forcing alone impacted future $\triangle S O C$ in LPJmL, ORCHIDEE-MICT, DLEM, and VISIT but had no obvious effect in LPJ-GUESS (Figures S4a and S4b).

Given the fact that differences in the projected $\triangle S O C$ are partly driven by different trends in NPP (see Equation 2), we further examined the simulated evolution of NPP with time (Figures 3, S4, and S5 for each model). All models simulated increased NPP in the future, of $7.3 \pm 3.2 \mathrm{Pg} \mathrm{C} \mathrm{yr}^{-1}(11.9 \pm 5.2 \%)$ under RCP 2.6 and of $18.3 \pm 4.9 \mathrm{Pg} \mathrm{C} \mathrm{yr}^{-1}(29.7 \pm 7.9 \%)$ under RCP 6.0 driven by CC + LUC (Figure 3d and Table S4). Similar to the uncertainty of $\triangle S O C$ (here, expressed as IQR), the uncertainty of $\triangle N P P$ mainly come from differences of TBMs and from the two RCP scenarios rather than from differences of GCM forcing, a result consistent with the dominant attribution of uncertainties on $\triangle S O C$ to differences of TBMs (Figure 3d).

An accelerated decomposition rate (increase of $k$; positive $\Delta k$ ) of global SOC was simulated by all models, with a mean increase of $2.8 \pm 1.0 \times 10^{-3} \mathrm{yr}^{-1}(8.0 \pm 3.9 \%)$ under RCP 2.6 and $7.7 \pm 1.8 \times 10^{-3} \mathrm{yr}^{-1}$ $(21.0 \pm 4.5 \%)$ under RCP 6.0, respectively (Figure $3 \mathrm{~g}$ and Table S5). Similar to the variations in the simulated global $\triangle S O C$ and global $\triangle N P P$, the spread of global decomposition rate $(\Delta k)$ among simulations were mostly attributed to differences in TBMs and RCPs rather than to differences of GCMs (Figure $3 \mathrm{~g}$ ).

\subsection{Contribution of Initial Soil Carbon, Decomposition Rate, and Soil Inputs to Soil Carbon Changes of Natural Ecosystems}

For the RCP 6.0 scenario, we decomposed model differences of $\triangle S O C$ into differences explained by soil inputs, decomposition rates, and initial soil carbon stocks using Equation 2. We found that these three variables altogether explain $84-91 \%$ of the variation in global $\triangle S O C$ across TBMs, this range being from the 


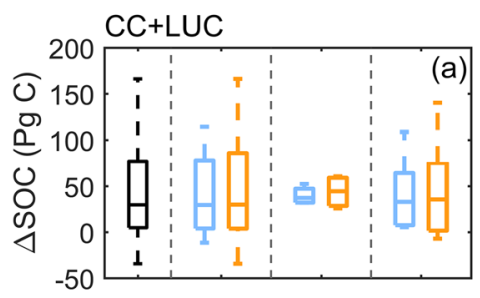

Only CC
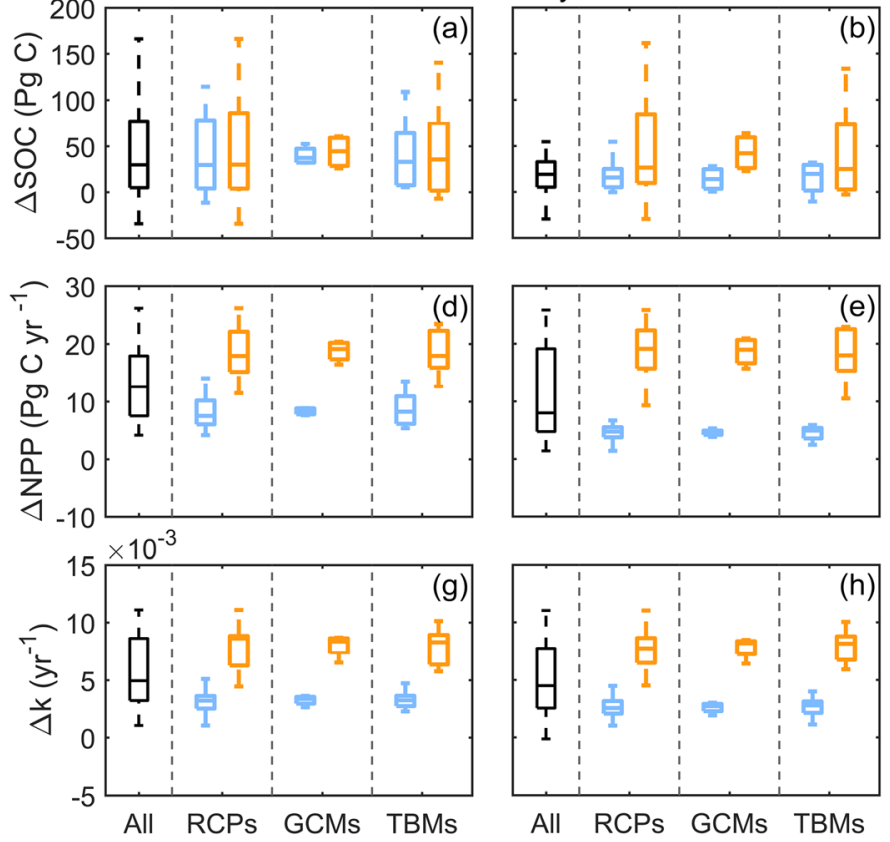
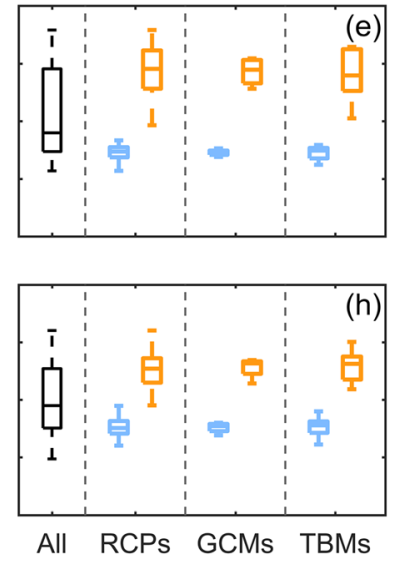

All data
Only LUC
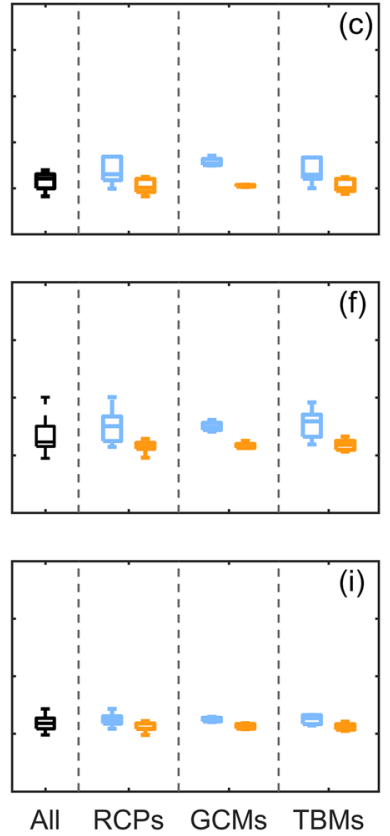

All RCPs GCMs TBMs

Figure 3. The interquartile range (IQR, the difference between 75th and 25th percentile of the data) change in global soil carbon $(\triangle S O C)$, net primarily productivity $(\triangle N P P)$, and decomposition rate $(\Delta k)$ according the effects of all data, RCPs (i.e., RCP 2.6 and RCP 6.0), GCMs (i.e., four climate forcing, including GFDL-ESM2M, HadGEM2-ES, IPSL-CM5ALR, and MIROC5), and TBMs (i.e., LPJ-GUESS, LPJmL, VISIT, and ORCHIDEE-MICT) under both effects of climate change and land use change (CC + LUC), the effect of climate change (only CC), and the effect of land use change (only LUC) over the period of 2090-2099 compared to the means of 1996-2005. "All" indicates the range obtained by averaging all data; "RCPs" indicates the range obtained by averaging all TBMs and GCMs outputs; "GCMs" indicates the range obtained by averaging all TBMs outputs for each GCM; and "TBMs" indicates the range obtained by averaging all GCMs outputs for each TBM.

different GCMs (all $p<0.1$; Figure 4). The initial soil carbon stocks and change in decomposition rate do not show significant correlation with global $\triangle S O C$ among TBMs, for any GCM. Instead, most of the $\triangle S O C$ differences between TBMs can be explained by their different changes in soil inputs (Figures $4 \mathrm{~d}, 4 \mathrm{i}, 4 \mathrm{n}$, and $4 \mathrm{~s}$ ). Different changes in soil inputs explain $52-89 \%$ of the global $\triangle S O C$ across the five TBMs, depending on the GCM considered (Figure 4). Regression slopes (between original modeled $\triangle S O C$ and predicted values from Equation 2) are similar between GCMs (ranging from 0.63 to 0.76; Figures 4a, 4f, $4 \mathrm{k}$, and 4p). For the RCP 2.6 scenario, no significant relationship between simulated $\triangle S O C$ and predicted values from Equation 2 was found across the different TBMs (Figure S6). This is because in RCP 2.6, climate change is small and $\mathrm{CO}_{2}$ concentration increases much less (63.9 ppm from 2005-2050) compared to RCP 6.0 (287.6 ppm from 2005-2099) and does not produce a change of SOC large enough to be attributed to the factors considered in Equation 2.

Using Equation 2, we further separated $\triangle S O C$ for tropical, temperate, and boreal regions (Figures 5-7). The relative changes in soil input, decomposition rates, and initial soil carbon stocks altogether explain 81-96\% of tropical $\triangle S O C$ (slopes from 0.58 to 0.83 ), $81-96 \%$ of temperate $\triangle S O C$ (slopes from 0.47 to 0.71 ), and $75-95 \%$ of boreal $\triangle S O C$ (slopes range from 0.26 to 0.45 ) (Figures 5-7). In the tropical region, most of $\triangle S O C$ differences between TBMs can be attributed to differences in changes of soil inputs $\left(R^{2}=0.43-0.92\right)$ and initial soil carbon $\left(R^{2}=0.44-0.90\right)$. For simulations driven by HadGEM2-ES GCM in the tropical region, initial soil carbon can explain more of the $\triangle S O C$ differences between TBMs than change in soil inputs (Figure 5). In both temperate and boreal regions, differences in changes in soil inputs explain most of the differences in $\triangle S O C$ across TBMs (Figures 6 and 7). 
Global natural ecosystem under RCP 6.0
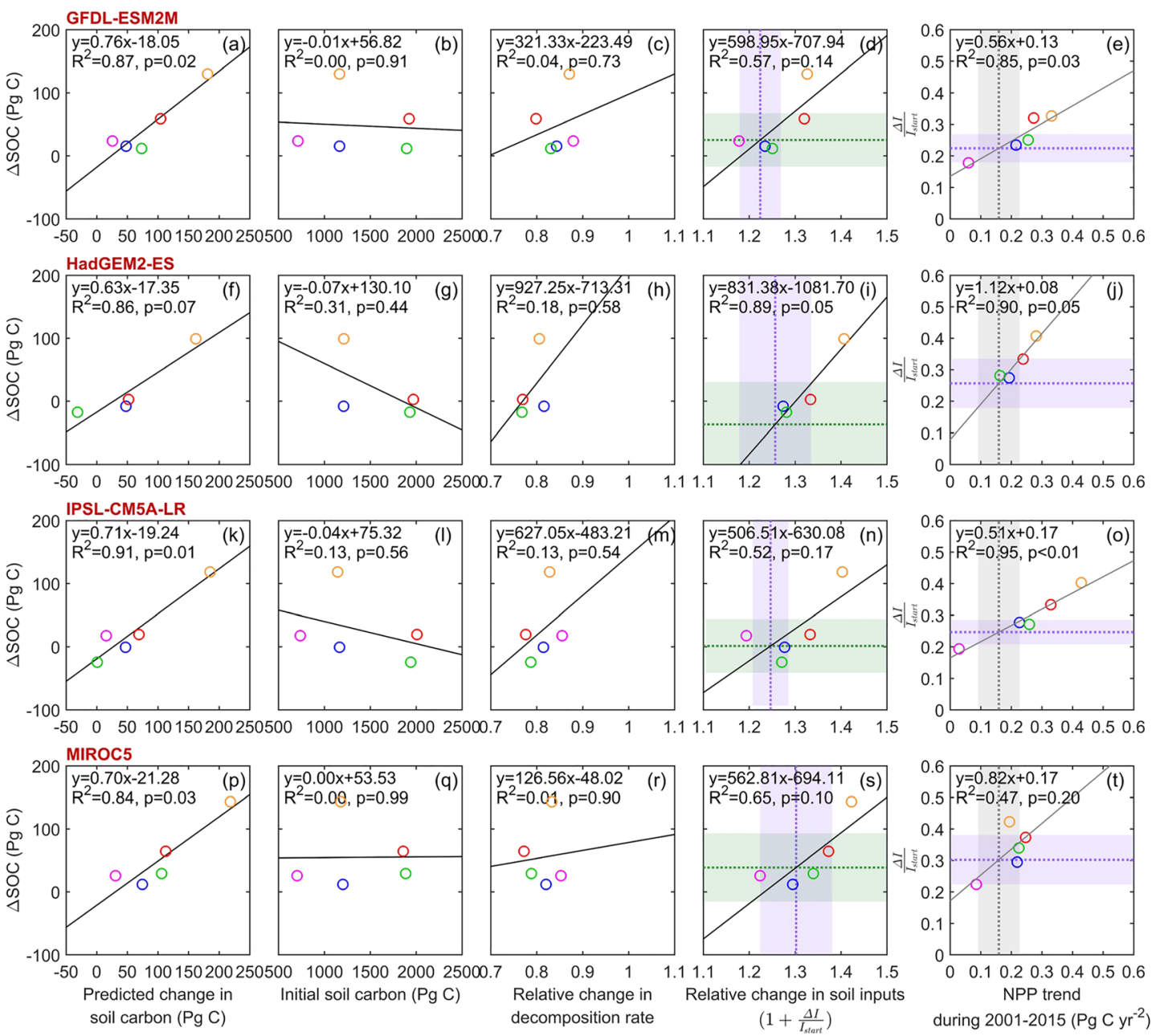

Model name

- LPJ-GUESS

LPJmL $\bullet$ VISIT

ORCHIDEE-MICT

Figure 4. Change in global soil carbon stocks in area dominated by natural ecosystems between start time (1995-2005) and end time (2090-2099) global means as a function of Equation $2(\mathrm{a}, \mathrm{f}, \mathrm{k}, \mathrm{p})$, the initial soil carbon stocks $\left(C_{\text {start }} ; \mathrm{b}, \mathrm{g}, \mathrm{l}, \mathrm{q}\right)$, the inverse of the relative change in decomposition rate $\left(\frac{1}{1+\frac{\Delta k}{k_{s t a r t}}}\right.$; , h, m, r), and the relative change in soil inputs $\left(1+\frac{\Delta I}{I_{\text {start }}} ; \mathrm{d}, \mathrm{i}, \mathrm{n}, \mathrm{s}\right)$, and the relationship between future input change $\left(\frac{I_{\text {end }}-I_{\text {start }}}{I_{\text {start }}}\right)$ and NPP trend during the period of 20012015 across the ISIMIP2b TBMs (e, j, o, t). All results shown here are from simulations driven by different GCMs' climate forcing under RCP 6.0 scenario. Group 2 simulations with climate change effect only are used. The different colors indicate different TBMs. The black lines indicate the linear regression across TBMs for each GCMs climate forcing. The dotted gray lines and gray areas indicate the observation-based NPP trend for the period 2001-2015. The dotted purple lines and purple areas indicate the constrained $\frac{\Delta I}{I_{\text {start }}}$ and $1+\frac{\Delta I}{I_{\text {start }}}$. The dotted green lines and green areas indicate the constrained $\Delta S O C$.

\subsection{Constraining Future $\triangle S O C$ by Observations}

\subsubsection{Constrained Global $\triangle S O C$ for Natural Vegetation}

As explained in section 2.3, we used observed NPP trends to constrain $\triangle S O C$ over grid cells dominated by natural vegetation (Figure $1 \mathrm{~b}$ ) for simulations driven by RCP 6.0. We recall here that the results of RCP 2.6 are not shown because they produced small $\triangle N P P$ and $\triangle S O C$ except for MIROC5 climate forcing in the tropical region (Figures S6-S9) and thus are not suitable for applying our emergent constraint approach (see section 2). We found significant linear relationships between modeled $\frac{\Delta I}{I_{\text {start }}}$ and modeled NPP trend during 2001-2015 across TBMs ( $R^{2}$ ranging from 0.85 to 0.95 ) for three out of four GCM forcing (GFDL-ESM2M, HadGEM2-ES, and IPSL-CM5A-LR). This is shown in Figure 4, the last column of plots. For MIROC5, the 
Natural ecosystem: Tropical region under RCP 6.0
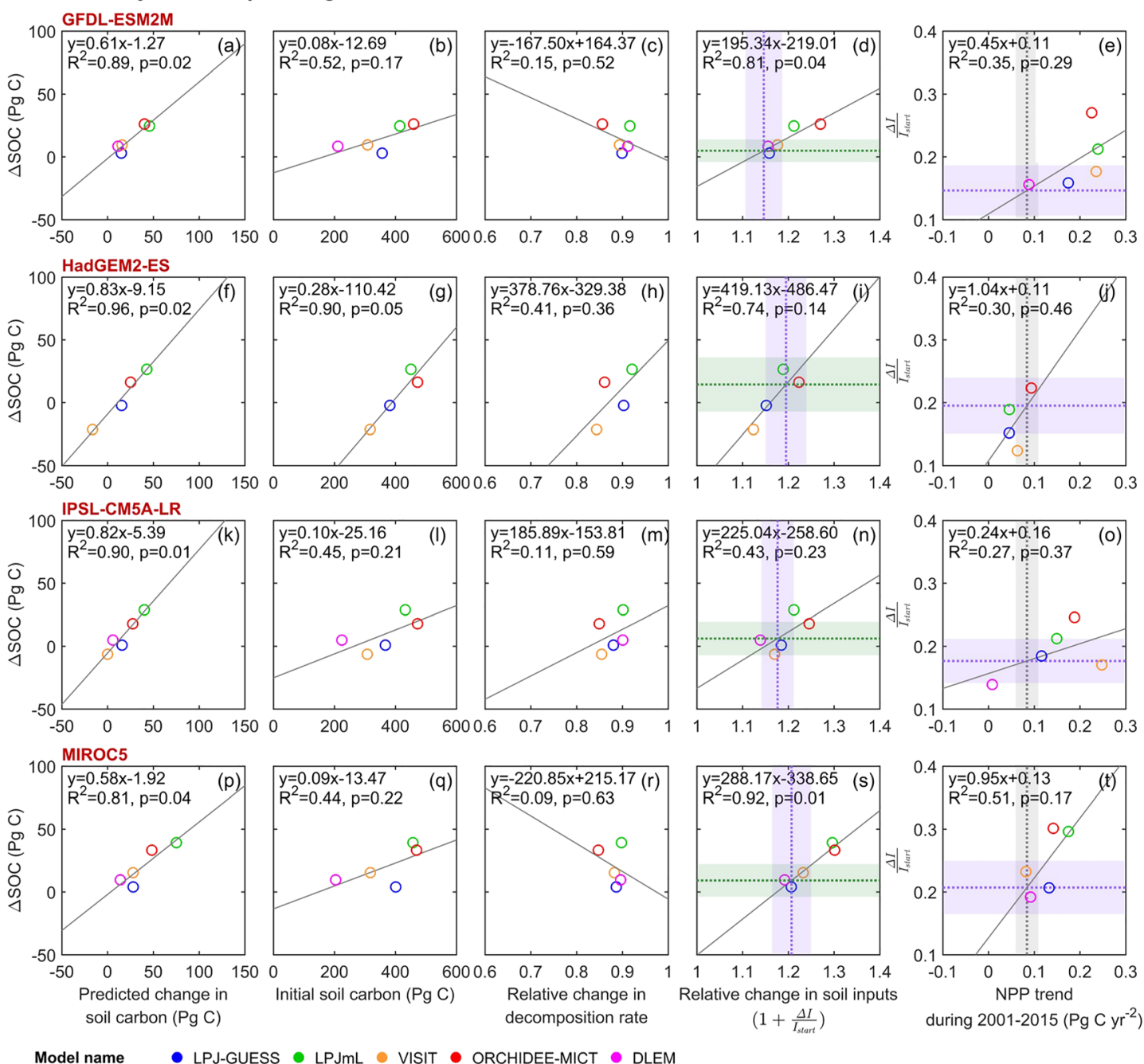

$\left(1+\frac{\Delta I}{I_{\text {tat }}}\right)$

during 2001-2015 (Pg C yr $\left.{ }^{-2}\right)$

Figure 5. Change in global soil carbon stocks in tropical region dominated by natural ecosystems between start time (1995-2005) and end time (2090-2099) global means as a function of Equation $2(\mathrm{a}, \mathrm{f}, \mathrm{k}, \mathrm{p})$, the initial soil carbon stocks $\left(C_{\text {start }} ; \mathrm{b}, \mathrm{g}, \mathrm{l}, \mathrm{q}\right)$, the inverse of the relative change in decomposition rate $\left(\frac{1}{1+\frac{\Delta k}{k_{\text {start }}}} ; \mathrm{c}, \mathrm{h}\right.$, $\mathrm{m}, \mathrm{r})$, and the relative change in soil inputs $\left(1+\frac{\Delta I}{I_{\text {start }}} ; \mathrm{d}, \mathrm{i}, \mathrm{n}, \mathrm{s}\right)$, and the relationship between future input change $\left(\frac{I_{\text {end }}-I_{\text {start }}}{I_{\text {start }}}\right)$ and NPP trend during the period of 2001-2015 across the ISIMIP2b models (e, j, o, t). Detailed symbol and line information are in Figure 4.

relationship between modeled $\frac{\Delta I}{I_{\text {start }}}$ and modeled NPP trend was not significant $\left(p=0.20 ; R^{2}=0.47\right.$; Figure 4t). Here, we use observed NPP trends (gray areas) and the linear relationships above to constrain future input changes $\frac{\Delta I}{I_{\text {start }}}$ (purple areas in Figures $4 \mathrm{e}, 4 \mathrm{j}, 4 \mathrm{o}$, and $4 \mathrm{t}$ ). Then, the constrained $\frac{\Delta I}{I_{\text {start }}}$ (purple areas in the fourth column of Figure 4) was used to constrain $\triangle S O C$ (green areas in Figures $4 \mathrm{~d}, 4 \mathrm{i}, 4 \mathrm{n}$, and $4 \mathrm{~s}$ ), according to the principle illustrated in Figure $1 \mathrm{~b}$.

Using the two-step emergent constraint with all uncertainties propagated (Equations 3 and 4), we constrained global $\triangle S O C$ values of $25.2 \pm 42.4 \mathrm{Pg} C$ with GFDL-ESM2M, $-36.9 \pm 67.3 \mathrm{Pg}$ C with HadGEM2ES, $1.4 \pm 42.6 \mathrm{Pg} \mathrm{C}$ with IPSL-CM5A-LR, and $38.8 \pm 54.1 \mathrm{Pg} \mathrm{C}$ with MIROC5 (Table 3 and Figure 4). These constrained global $\triangle S O C$ values were all lower than the original ensemble means of $\triangle S O C$ (Figure 4 and Table 3). For HadGEM2-ES, the constrained global $\triangle S O C$ was even constrained to be a net 
Natural ecosystem: Temperate region under RCP 6.0
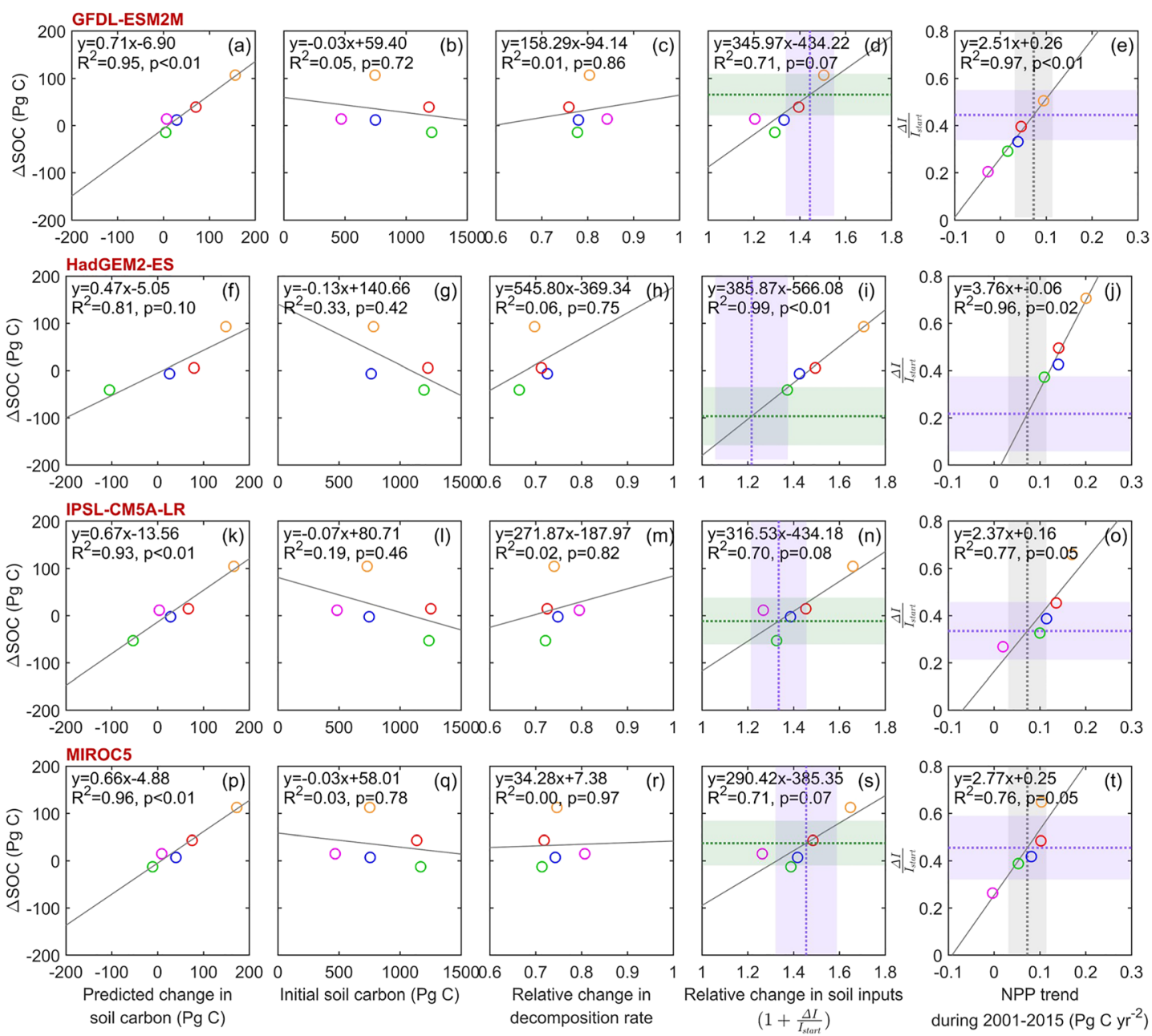

Model name

- LPJ-GUESS • LPJML • VISI

- ORCHIDEE-MICT • DLEM

Figure 6. Change in global soil carbon stocks in temperate region dominated by natural ecosystems between start time (1995-2005) and end time (2090-2099) global means as a function of Equation $2(\mathrm{a}, \mathrm{f}, \mathrm{k}, \mathrm{p})$, the initial soil carbon stocks $\left(C_{\text {start }} ; \mathrm{b}, \mathrm{g}, \mathrm{l}, \mathrm{q}\right)$, the inverse of the relative change in decomposition rate $\left(\frac{1}{1+\frac{\Delta k}{k_{\text {start }}}} ; \mathrm{c}, \mathrm{h}, \mathrm{m}, \mathrm{r}\right)$, and the relative change in soil inputs $\left(1+\frac{\Delta I}{I_{\text {start }}} ; \mathrm{d}, \mathrm{i}, \mathrm{n}, \mathrm{s}\right)$, and the relationship between future input change $\left(\frac{I_{\text {end }}-I_{\text {start }}}{I_{\text {start }}}\right)$ and $\mathrm{NPP}$ trend during the period of 2001-2015 across the ISIMIP2b models (e, j, o, t). Detailed symbol and line information are in Figure 4.

loss, whereas it was simulated as a gain in the original ensemble mean of the TBMs $(19.0 \pm 53.9 \mathrm{Pg}$ C). We acknowledged that uncertainties of observed NPP trends combined with uncertainties in the regressions led to only a marginal uncertainty reduction of constrained versus original $\triangle S O C$, given the small set of TBMs examined in this study. The linear relationships shown in Figure 4 were based only on five TBMs, and a larger ensemble of models should make the emergent constraint more effective, with more expected model outliers. Here, we found that 15 out of 19 of the original $\triangle S O C$ simulations were within 1-sigma uncertainty of constrained $\triangle S O C$, one outlier being the VISIT model (Figure 4 and Table 3).

\subsubsection{Constrained Regional $\triangle S O C$ for Natural Vegetation}

Significant linear relationships between modeled $\frac{\Delta I}{I_{\text {start }}}$ and modeled NPP trends during 2001-2015 were found in all GCMs in the temperate region for natural vegetation (Figures $6 \mathrm{e}, 6 \mathrm{j}, 6 \mathrm{o}$, and $6 \mathrm{t}$ ) and in one GCM (i.e., HadGEM2-ES) forcing in the boreal region (Figure 7j), but not in the tropical region (Figures $5 \mathrm{e}, 5 \mathrm{j}, 5 \mathrm{o}$, and $5 \mathrm{t}$ ). Constrained temperate $\triangle S O C$ showed large differences between different GCMs (Table 3 and Figure 6), ranging from $-96.5 \pm 61.7$ Pg C for HadGEM2-ES to $65.5 \pm 44.2 \mathrm{Pg}$ C for 
Natural ecosystem: Boreal region under RCP 6.0
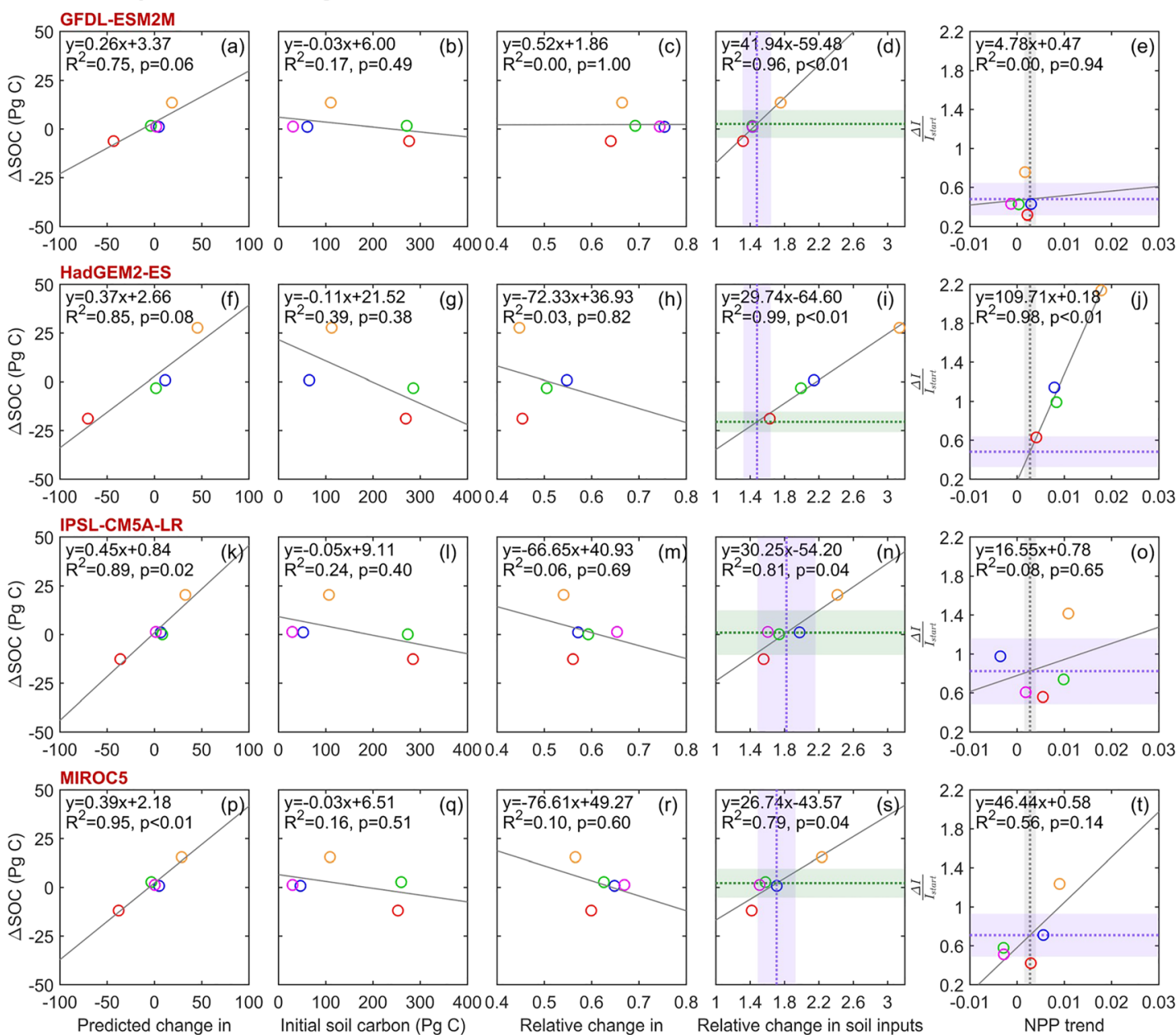

soil carbon $(\mathrm{Pg} \mathrm{C})$

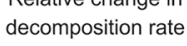

$\begin{array}{lllll}1.4 & 1.8 & 2.2 & 2.6 & 3\end{array}$

$\left(1+\frac{\Delta I}{I_{\text {start }}}\right)$

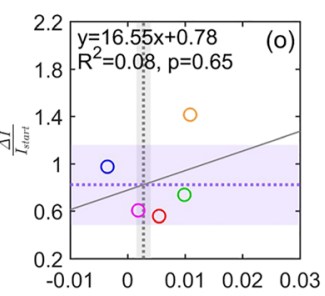

Model name

- LPJ-GUESS • LPJML • VISIT • ORCHIDEE-MICT • DLEM

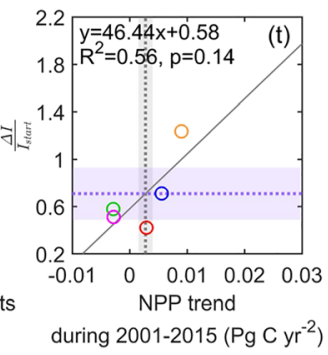

Figure 7. Change in global soil carbon stocks in boreal region dominated by natural ecosystems between start time (1995-2005) and end time (2090-2099) global means as a function of Equation 2 ( $\mathrm{a}, \mathrm{f}, \mathrm{k}, \mathrm{p})$, the initial soil carbon stocks $\left(C_{\text {start }} ; \mathrm{b}, \mathrm{g}, \mathrm{l}, \mathrm{q}\right)$, the inverse of the relative change in decomposition rate $\left(\frac{1}{1+\frac{\Delta k}{k_{\text {start }}}} ; \mathrm{c}, \mathrm{h}, \mathrm{m}, \mathrm{r}\right)$, and the relative change in soil inputs $\left(1+\frac{\Delta I}{I_{\text {start }}} ; \mathrm{d}, \mathrm{i}, \mathrm{n}, \mathrm{s}\right)$, and the relationship between future input change $\left(\frac{I_{\text {end }}-I_{\text {start }}}{I_{\text {start }}}\right)$ and NPP trend during the period of 2001-2015 across the ISIMIP2b models (e, j, o, t). Detailed symbol and line information are in Figure 4.

GFDL-ESM2M. Constrained $\triangle S O C$ in the temperate region can be either higher than (driven by GFDLESM2M and MIROC5 climate) or lower than (driven by HadGEM2-ES and IPSL-CM5A-LR climate) the original model ensemble mean (Table 3). The uncertainty range of constrained temperate $\triangle S O C$ is slightly reduced with GFDL-ESM2M, IPSL-CM5A-LR, and MIROC5 climate (by 3.6-13.2 Pg C). With HadGEM2-ES climate, the uncertainty range of constrained $\triangle S O C$ was not reduced, because observed NPP trends are much smaller than in the model ensemble forced by this GCM, and constrained $\triangle S O C$ is extrapolated outside the range of TBMs in Table 3. For temperate region only 10 out of 19 constrained $\triangle S O C$ values were within the 1-sigma uncertainty of the original $\triangle S O C$ ensemble, which indicates that observed NPP trends imply a strong change of constrained versus original SOC changes and thus that the quality of observational data is critical.

The lower constrained $\triangle S O C$ values obtained for HadGEM2-ES climate compared to other GCMs, globally and for the temperate and boreal regions, are due to the much higher regression slope and lower intercept between $\frac{\Delta I}{I_{\text {start }}}$ and observed NPP trend for this GCM, which caused lower constrained $1+\frac{\Delta I}{I_{\text {start }}}$ and thus 
Table 3

Modeled $\triangle$ SOC (Unit, Pg C), Constrained $\triangle$ SOC by NPP Trends Over the Period of 2001-2015 and Constrained $\triangle$ SOC by Initial SOC (1995-2005) Under RCP 6.0 Scenario in Natural Vegetation Grid Cells (Exclude the Cropland) and Its Different Climate Region Across Different GCMs

\begin{tabular}{|c|c|c|c|c|c|c|c|c|c|}
\hline \multirow[b]{2}{*}{ Classification } & & \multicolumn{2}{|c|}{ Modeled $\triangle S O C$} & \multicolumn{3}{|c|}{ Constrained $\triangle S O C$ by NPP } & \multicolumn{3}{|c|}{ Constrained $\triangle S O C$ by initial SOC } \\
\hline & & Mean & $1 \sigma$ & Mean & $1 \sigma$ & Within $1 \sigma$ uncertainty & Mean & $1 \sigma$ & Within $1 \sigma$ uncertainty \\
\hline \multirow{5}{*}{ Global } & Natural vegetation & & & & & & & & \\
\hline & GFDL-ESM2M & 47.9 & 49.4 & 25.2 & 42.2 & 4.0 & 49.0 & 0.6 & 0 \\
\hline & HadGEM2-ES & 19.0 & 53.9 & -36.9 & 67.3 & 3.0 & 45.6 & 6.8 & 0 \\
\hline & IPSL-CM5A-LR & 26.1 & 54.6 & 1.4 & 42.6 & 4.0 & 33.1 & 3.4 & 0 \\
\hline & MIROC5 & 54.9 & 53.1 & 38.8 & 54.1 & 4.0 & 54.8 & 0.1 & 0 \\
\hline Climate & Tropical region & & & & & & & & \\
\hline \multirow[t]{14}{*}{ Region } & GFDL-ESM2M & 14.4 & 10.4 & 4.9 & 9.0 & 3.0 & 16.1 & 0.6 & 0 \\
\hline & HadGEM2-ES & 4.7 & 21.1 & 14.4 & 21.6 & 3.0 & -4.8 & 2.3 & $\mathbf{0}$ \\
\hline & IPSL-CM5A-LR & 9.3 & 14.1 & 6.2 & 13.3 & 4.0 & 10.3 & 0.8 & 0 \\
\hline & MIROC5 & 20.3 & 15.2 & 9.2 & 13.0 & 3.0 & 20.5 & 0.7 & 0 \\
\hline & Temperate region & & & & & & & & \\
\hline & GFDL-ESM2M & 31.3 & 46.2 & 65.5 & 44.2 & 2.0 & 36.3 & 2.0 & 0 \\
\hline & HadGEM2-ES & 12.7 & 56.8 & -96.5 & 61.7 & 1.0 & 48.1 & 8.0 & 0 \\
\hline & IPSL-CM5A-LR & 14.8 & 57.0 & -11.6 & 49.5 & 4.0 & 27.6 & 4.6 & 0 \\
\hline & MIROC5 & 32.9 & 48.8 & 37.2 & 47.0 & 3.0 & 37.0 & 1.8 & 0 \\
\hline & Boreal region & & & & & & & & \\
\hline & GFDL-ESM2M & 2.2 & 7.1 & 2.5 & 7.1 & 3.0 & 3.1 & 1.1 & 0 \\
\hline & HadGEM2-ES & 1.6 & 19.3 & -20.6 & 5.2 & 1.0 & 9.2 & 4.7 & 0 \\
\hline & IPSL-CM5A-LR & 2.0 & 11.8 & 0.9 & 11.4 & 3.0 & 3.7 & 2.1 & 0 \\
\hline & MIROC5 & 1.6 & 9.7 & 2.1 & 7.4 & 3.0 & 2.6 & 1.5 & 2 \\
\hline
\end{tabular}

Note. The number indicates the number of TBMs with modeled $\triangle S O C$ within 1-sigma uncertainty of the constrained $\triangle S O C$. Bold values indicate the constrained $\triangle S O C$ based on a significant relationship between $\triangle S O C$ and NPP or initial SOC, respectively. A $p$ value $\leq 0.1$ was considered significant.

lower constrained $\triangle S O C$. In the tropical region, however, the constrained $\triangle S O C$ for HadGEM2-ES is significantly higher than under the other GCMs because less TBMs used this GCM; DLEM did not provide HadGEM2-ES GCM output, and Figure S10 shows the results after excluding DLEM. In addition, the uncertainty of the constrained $\triangle S O C$ from HadGEM2-ES is larger than those from other GCMs, due to the high regression slope between $\triangle S O C$ and $1+\frac{\Delta I}{I_{\text {start }}}$ (simulations driven by HadGEM2-ES have the highest slopes globally and in tropical and temperate regions), and the uncertainty of constrained $\frac{\Delta I}{I_{\text {start }}}$ is determined by the regression slope between $\frac{\Delta I}{I_{\text {start }}}$ and modeled NPP trend.

We found no strong relationships between $\triangle S O C$ and initial soil carbon across TBMs at global scale (Figure 4) unlike what could be theoretically expected from section 2.3, which prevents us from using observed global initial SOC stocks to constrain future $\triangle S O C$. However, there are positive relationships in the tropics but significant only for the HadGEM2-ES GCM $\left(R^{2}=0.90, p=0.05\right.$; Figure $\left.5 \mathrm{~g}\right)$. A lower constrained $\triangle S O C$ was found from HadGEM2-ES $(-4.8 \pm 2.3 \mathrm{Pg} \mathrm{C})$ than in the original ensembles $(4.7 \pm 21.1 \mathrm{Pg} C)$ using initial SOC stocks as a constraint. Such constrained $\triangle S O C$ was smaller than that constrained by NPP trend $(14.4 \pm 21.6 \mathrm{Pg}$ C; Figure 5 and Table 3). It should be noted that none of the constrained $\triangle S O C$ values were within a 1-sigma uncertainty of the original $\triangle S O C$ ensemble in such constrained $\triangle S O C$ (Figure S11).

\subsubsection{Constrained Future $\triangle S O C$ From Cropland Expansion}

We found a significant positive relationship between the simulated SOC density changes across grid cells with cropland expansion $\Delta s o c_{\text {cropland expansion }}$ and the soil carbon density difference between cropland in

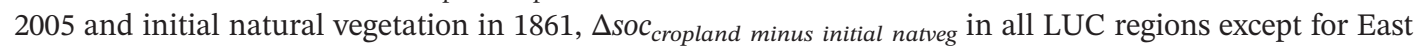
Asia (Figure 8). The coefficient of determination $\left(R^{2}\right)$ of those relationships is high in all regions (ranging from 0.79 to 0.97 across regions) except for South Asia $\left(R^{2}=0.49\right)$. That means the $\triangle S O C$ due to LUC outweighs $\triangle S O C$ due to climate change over grid cells with cropland expansion. The slopes of the

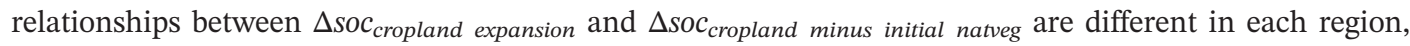
ranging from $0.90 \mathrm{~kg} \mathrm{C} \mathrm{m}^{-2}\left(\mathrm{~kg} \mathrm{C} \mathrm{m}^{-2}\right)^{-1}$ in South Asia to $3.15 \mathrm{~kg} \mathrm{C} \mathrm{m}^{-2}\left(\mathrm{~kg} \mathrm{C} \mathrm{m}^{-2}\right)^{-1}$ in West Eurasia. 


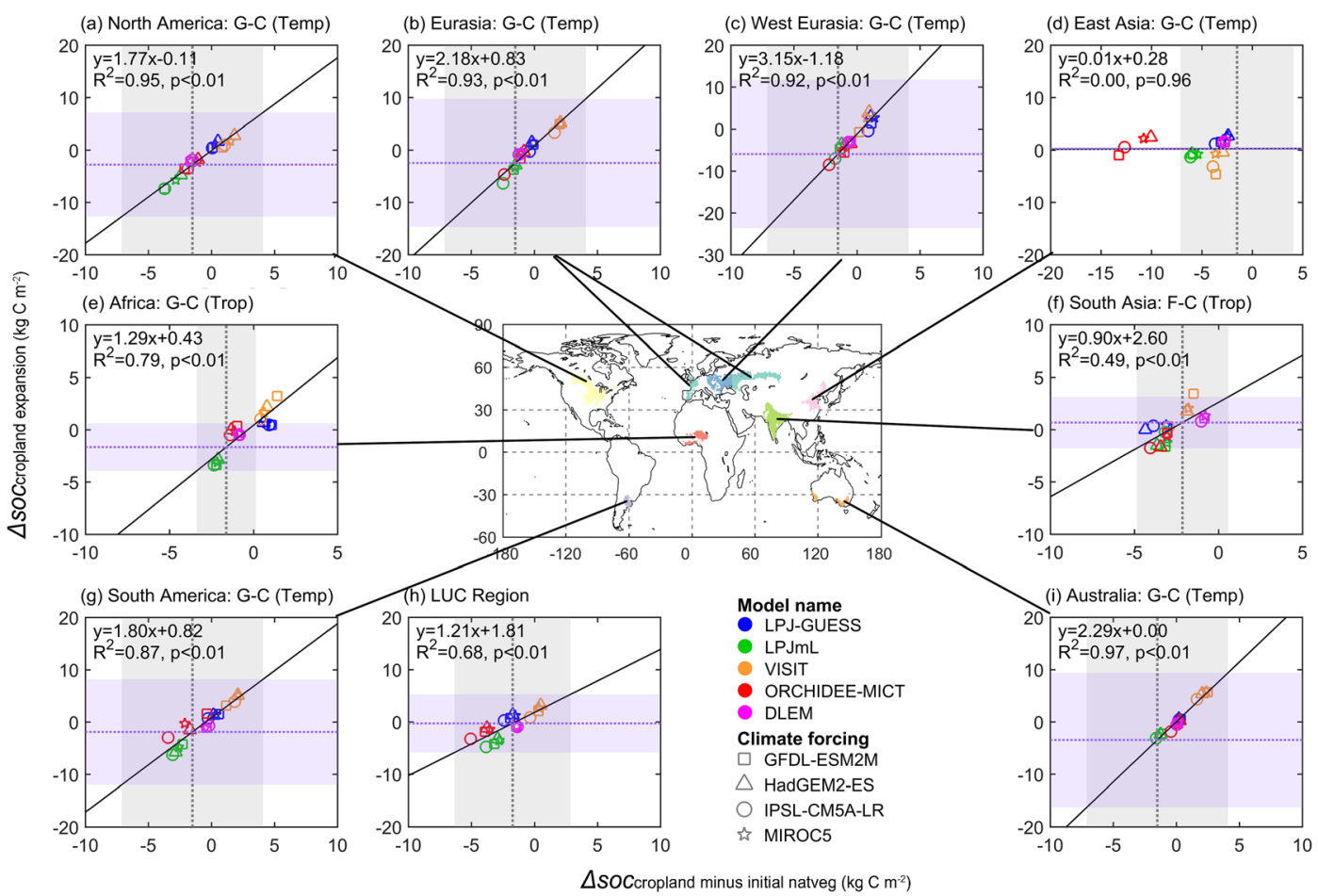

Figure 8. Relationship between modeled SOC density changes across cropland expansion area ( $\Delta \operatorname{soc}_{\text {cropland }}$ expansion) during the period of 1861-2005 and the soil carbon density difference ( $\left.\Delta s c_{\text {cropland minus initial natveg }}\right)$ between current cropland (in 2005) and initial natural vegetation (in 1861). Group 1 simulations were used in this analysis. The bottom center panel shows the results at global land use-dominated areas. The different colors and symbols indicate different climate forcing and models, respectively. The black lines indicate the linear regression across all TBMs and all GCMs. The dotted gray lines and gray areas indicate the observation-based meta-analysis data. The dotted purple lines and purple areas indicate the constrained $\Delta s c_{\text {cropland expansion. }}$

Following the emergent constraint principle described in section 2, we constrain $\Delta$ Soc $_{\text {cropland expansion }}$ from

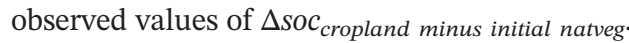

In LUC-dominated areas, the constrained global $\Delta s o c_{\text {cropland expansion }}$ was $-0.29 \pm 5.56 \mathrm{~kg} \mathrm{C} \mathrm{m}^{-2}$, which is a smaller loss than the original modeled range of $-0.61 \pm 2.15 \mathrm{~kg} \mathrm{C} \mathrm{m}^{-2}$, but this constrained value has a large uncertainty (Figures 8 and S3 and Table 4). However, larger constrained carbon loss ( $\left.\Delta s c_{\text {cropland expansion }}\right)$ than from the unconstrained simulations was found in Eurasia, North America, South America, Africa,

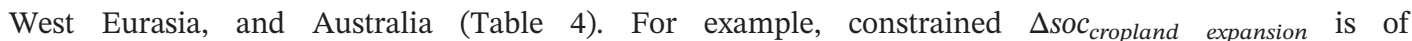
$-2.78 \pm 9.92 \mathrm{~kg} \mathrm{C} \mathrm{m}^{-2}$ in North America compared to the original mean value of $-1.43 \pm 2.85 \mathrm{~kg} \mathrm{C} \mathrm{m}^{-2}$ for that region. Constrained $\Delta s o c_{\text {cropland expansion }}$ is a loss of $-3.45 \pm 12.84 \mathrm{~kg} \mathrm{C} \mathrm{m}^{-2}$ in Australia compared to the original ensemble mean of $0.45 \pm 2.53 \mathrm{~kg} \mathrm{C} \mathrm{m}^{-2}$. In addition, large differences in constrained

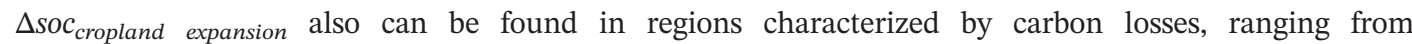
$-5.94 \pm 17.68 \mathrm{~kg} \mathrm{C} \mathrm{m}^{-2}$ (West Eurasia) to $-1.66 \pm 2.27 \mathrm{~kg} \mathrm{C} \mathrm{m}^{-2}$ (Africa).We found that all simulated $\Delta s o c_{\text {cropland expansion }}$ is within 1-sigma uncertainty of the constrained values in LUC region (Figure 8 and Table 4), but the spread of constrained $\Delta s o c$ is always larger than that in the original model ensemble.

By multiplying these constrained changes of SOC densities by the area of historical cropland expansion, we constrained a carbon loss induced by cropland expansion of $-1.03 \pm 19.94$ Pg C during 1861-2005 (Table 5). There are differences between regions of historical cropland expansion, with a maximum loss in North America ( $-2.79 \pm 9.96 \mathrm{Pg} \mathrm{C})$, a minimum loss in South America $(-0.36 \pm 1.92 \mathrm{Pg} \mathrm{C})$, and a neutral carbon change in East Asia $(0.05 \pm 0.01 \mathrm{Pg} \mathrm{C})$ and South Asia $(0.42 \pm 1.53 \mathrm{Pg} \mathrm{C})$.

Future regional SOC changes associated with cropland expansion were constrained by multiplying future cropland expansion areas (Figure S12) by constrained estimates of $\Delta$ soc $_{\text {cropland expansion }}$ (Table 5). We inferred small future carbon losses from future cropland expansion for RCP 2.6 and RCP 6.0 in Eurasia, 


\section{Table 4}

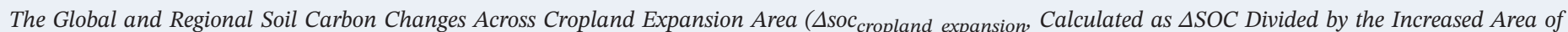

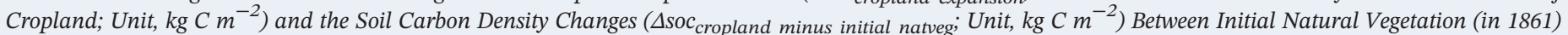
and Current Cropland (in 2005) From Original ISIMIP2b Models and From the Estimate Constrained by Meta-Analysis Data (Dsoc cropland minus initial natveg; Unit, $\mathrm{kg} \mathrm{C} \mathrm{m}^{-2}$ ) in Land Use-Dominated Areas

\begin{tabular}{|c|c|c|c|c|c|c|}
\hline \multirow[b]{2}{*}{ Region } & \multirow[b]{2}{*}{ LUC type } & \multicolumn{2}{|c|}{$\Delta$ soc $_{\text {cropland minus initial natveg }}$} & \multicolumn{3}{|c|}{$\Delta$ soc $_{\text {cropland expansion }}$} \\
\hline & & Meta-analysis & ISMIP2b & Constrained & ISMIP2b & Number \\
\hline Eurasia & G-C (temp) & $-1.51 \pm 5.61$ & $-0.39 \pm 1.32$ & $-2.46 \pm 12.22$ & $-0.15 \pm 2.95$ & 19 \\
\hline North America & G-C (temp) & $-1.51 \pm 5.61$ & $-0.76 \pm 1.57$ & $-2.78 \pm 9.92$ & $-1.43 \pm 2.85$ & 19 \\
\hline South America & G-C (temp) & $-1.51 \pm 5.61$ & $-0.50 \pm 1.62$ & $-1.89 \pm 10.08$ & $-0.22 \pm 3.09$ & 19 \\
\hline Africa & G-C (trop) & $-1.62 \pm 1.76$ & $-0.42 \pm 1.16$ & $-1.66 \pm 2.27$ & $-0.18 \pm 1.67$ & 14 \\
\hline West Eurasia & G-C (temp) & $-1.51 \pm 5.61$ & $-0.27 \pm 0.99$ & $-5.94 \pm 17.68$ & $-1.82 \pm 3.35$ & 19 \\
\hline Australia & G-C (temp) & $-1.51 \pm 5.61$ & $0.20 \pm 1.09$ & $-3.45 \pm 12.84$ & $0.45 \pm 2.53$ & 19 \\
\hline South Asia & F-C (trop) & $-2.14 \pm 2.72$ & $-2.25 \pm 1.45$ & $0.67 \pm 2.45$ & $0.12 \pm 1.28$ & 18 \\
\hline East Asia & G-C (temp) & $-1.51 \pm 5.61$ & $-4.52 \pm 3.85$ & $0.27 \pm 0.03$ & $0.20 \pm 1.81$ & 0 \\
\hline LUC region & - & $-1.74 \pm 4.61$ & $-1.74 \pm 1.66$ & $-0.29 \pm 5.56$ & $-0.61 \pm 2.15$ & 19 \\
\hline
\end{tabular}

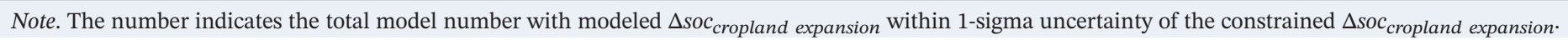

North America, South America, Africa, West Eurasia, and Australia and small carbon gains in South Asia and East Asia (Table 5). In North America, no cropland expansion occurs under RCP 6.0. Overall, there is no large cropland expansion. Global constrained carbon losses from future cropland expansion are $-0.19 \pm 3.72 \mathrm{Pg} \mathrm{C}$ for RCP 2.6 and $-0.18 \pm 3.52 \mathrm{Pg}$ C for RCP 6.0, respectively.

\subsection{Comparison of Initial SOC Stocks for Natural Vegetation}

We compared initial soil carbon stocks between modeled and observed data sets for grid cells with natural vegetation. The mean global soil carbon stock over the period of 1995-2005 across all GCMs and TBMs was 1,421.6 Pg C with a range of 702.6-2,008.3 Pg C (Table 6). The mean value was higher than that from three data sets of 1,202.4 Pg C, but the observed range of 1,094.8-1,283.9 Pg C was much smaller than the spread of models, indicating that even with the same climate forcing, models are inconsistent with the observed SOC stocks (Table 6). Yet there was a slightly smaller spread between ISIMIP2b TBMs than the CMIP5 ESMs, which gave a mean value of 1,520 Pg C and a range of 510-3,040 Pg C (Todd-Brown et al., 2013). DLEM forced by MIROC5 has the lowest SOC (702.6 Pg C), and ORCHIDEE-MICT forced by IPSL-CM5A-LR has the highest value (2,008.3 Pg C). In temperate region, SOC from all GCMs and TBMs had a median value of 762.8 Pg C with an IQR of 708.5 Pg C, slightly higher but comparable to the observed value (mean 717.3 Pg C with a range of 645.9-758.0 Pg C across data sets). Modeled SOC in the tropical region had a median value of 381.6 Pg C with an IQR of 231.6 Pg C, consistent with observed data sets (mean

Table 5

The Estimated Regional Soil Carbon Change (SSOC, Pg C) Due to Land Use Change in Historical (1861-2005) and Future Period (2005-2099)

\begin{tabular}{|c|c|c|c|c|c|c|c|}
\hline \multirow[b]{3}{*}{ Region } & \multirow{3}{*}{$\begin{array}{c}\text { Modeled } \\
\text { Historical } \\
\triangle S O C\end{array}$} & \multicolumn{6}{|c|}{ Estimated $\triangle S O C$} \\
\hline & & \multicolumn{2}{|c|}{ Historical } & \multicolumn{2}{|c|}{ RCP 2.6} & \multicolumn{2}{|c|}{ RCP 6.0} \\
\hline & & Area & $\triangle S O C$ & Area & $\triangle S O C$ & Area & $\triangle S O C$ \\
\hline Eurasia & $-0.08 \pm 1.32$ & 0.406 & $-1.00 \pm 4.96$ & 0.020 & $-0.05 \pm 0.24$ & 0.011 & $-0.03 \pm 0.14$ \\
\hline North America & $-1.74 \pm 3.08$ & 1.004 & $-2.79 \pm 9.96$ & 0.039 & $-0.11 \pm 0.38$ & 0.000 & 0 \\
\hline South America & $-0.05 \pm 0.65$ & 0.190 & $-0.36 \pm 1.92$ & 0.179 & $-0.34 \pm 1.80$ & 0.152 & $-0.29 \pm 1.53$ \\
\hline Africa & $-0.09 \pm 0.75$ & 0.408 & $-0.68 \pm 0.93$ & 0.251 & $-0.42 \pm 0.57$ & 0.120 & $-0.20 \pm 0.27$ \\
\hline West Eurasia & $-0.10 \pm 1.62$ & 0.452 & $-2.69 \pm 8.00$ & 0.009 & $-0.05 \pm 0.15$ & 0.001 & $-0.01 \pm 0.03$ \\
\hline Australia & $0.18 \pm 0.93$ & 0.334 & $-1.15 \pm 4.28$ & 0.001 & $-0.003 \pm 0.002$ & 0.001 & $-0.002 \pm 0.007$ \\
\hline South Asia & $0.09 \pm 0.88$ & 0.623 & $0.42 \pm 1.53$ & 0.163 & $0.11 \pm 0.40$ & 0.348 & $0.23 \pm 0.85$ \\
\hline East Asia & $0.04 \pm 0.34$ & 0.171 & $0.05 \pm 0.01$ & 0.009 & $0.002 \pm 0.001$ & $<0.0001$ & $<0.0001$ \\
\hline LUC region & $-2.64 \pm 8.43$ & 3.588 & $-1.03 \pm 19.94$ & 0.670 & $-0.19 \pm 3.72$ & 0.633 & $-0.18 \pm 3.52$ \\
\hline
\end{tabular}

Note. The estimated $\triangle S O C$ of each region was equal to the constrainted $\Delta \operatorname{soc}_{\text {cropland expansion }}\left(\mathrm{kg} \mathrm{C} \mathrm{m}^{-2}\right)$ mutiply by its crop expansion area $\left(10^{12} \mathrm{~m}^{2}\right)$. There is no crop expansion under RCP 6.0 in North America. 
Table 6

Global and Natural Ecosystem Initial Soil Carbon Stocks From Different Database (Without Permafrost C) and GCMs During the Period of 1995-2005 at Soil Depth of $0-1 \mathrm{~m}$

\begin{tabular}{|c|c|c|c|c|c|c|}
\hline \multirow[b]{2}{*}{ Database/TBMs } & \multirow[b]{2}{*}{ Data/GCMs } & \multirow{2}{*}{$\begin{array}{l}\text { Global } \\
(\text { Pg C) }\end{array}$} & \multicolumn{4}{|c|}{ Natural ecosystem $(\operatorname{Pg} C)$} \\
\hline & & & Tropical & Temperate & Boreal & Total \\
\hline \multirow{4}{*}{ Database } & HWSD & $1,265.8$ & 376.4 & 645.9 & 72.6 & $1,094.9$ \\
\hline & WISE30sec & $1,419.8$ & 362.4 & 758.0 & 108.1 & $1,228.5$ \\
\hline & HWSD + NCSCD & $1,454.4$ & 376.5 & 748.1 & 159.3 & $1,283.9$ \\
\hline & Mean & $1,380.0$ & 371.8 & 717.3 & 113.3 & $1,202.4$ \\
\hline \multirow[t]{4}{*}{ LPJ-GUESS } & GFDL-ESM2M & $1,340.0$ & 356.4 & 748.7 & 61.0 & $1,166.1$ \\
\hline & HadGEM2-ES & $1,380.5$ & 381.6 & 762.8 & 65.3 & $1,209.7$ \\
\hline & IPSL-CM5A-LR & $1,357.4$ & 367.0 & 746.2 & 52.3 & $1,165.5$ \\
\hline & MIROC5 & $1,380.9$ & 401.1 & 755.1 & 46.4 & $1,202.6$ \\
\hline \multirow[t]{4}{*}{ LPJmL } & GFDL-ESM2M & $2,024.9$ & 414.5 & $1,210.3$ & 271.6 & $1,896.3$ \\
\hline & HadGEM2-ES & $2,055.3$ & 450.6 & $1,195.5$ & 285.3 & $1,931.4$ \\
\hline & IPSL-CM5A-LR & $2,074.2$ & 432.3 & $1,235.5$ & 273.7 & $1,941.5$ \\
\hline & MIROC5 & $2,012.5$ & 457.5 & $1,168.7$ & 259.7 & $1,885.9$ \\
\hline \multirow[t]{4}{*}{ VISIT } & GFDL-ESM2M & $1,287.6$ & 308.6 & 745.8 & 110.8 & $1,165.2$ \\
\hline & HadGEM2-ES & $1,334.8$ & 317.0 & 782.4 & 112.7 & $1,212.1$ \\
\hline & IPSL-CM5A-LR & $1,271.5$ & 307.8 & 729.6 & 106.9 & $1,144.3$ \\
\hline & MIROC5 & $1,302.4$ & 317.6 & 751.1 & 109.1 & $1,177.8$ \\
\hline \multirow[t]{4}{*}{ ORCHIDEE-MICT } & GFDL-ESM2M & $2,164.6$ & 459.8 & $1,187.9$ & 276.6 & $1,924.4$ \\
\hline & HadGEM2-ES & $2,207.6$ & 472.4 & $1,227.5$ & 269.6 & $1,969.5$ \\
\hline & IPSL-CM5A-LR & $2,269.9$ & 472.8 & $1,250.9$ & 284.7 & $2,008.3$ \\
\hline & MIROC5 & $2,099.1$ & 469.4 & $1,136.0$ & 252.9 & $1,858.2$ \\
\hline \multirow[t]{3}{*}{ DLEM } & GFDL-ESM2M & 790.3 & 211.0 & 469.9 & 30.8 & 711.7 \\
\hline & IPSL-CM5A-LR & 817.2 & 224.4 & 483.5 & 29.1 & 737.0 \\
\hline & MIROC5 & 780.3 & 204.0 & 468.8 & 29.7 & 702.6 \\
\hline Model mean & & $1,576.4$ & 369.8 & 897.7 & 154.1 & $1,421.6$ \\
\hline Model median & & $1,380.5$ & 381.6 & 762.8 & 110.8 & $1,209.7$ \\
\hline Model IQR & & $1,250.7$ & 231.6 & 708.5 & 238.6 & $1,175.7$ \\
\hline
\end{tabular}

Note. The bold and bold-italic indicate the largest and smallest values, respectively. The total indicates the total soil carbon in grid cells dominated by natural vegetation where the cropland fraction is less than $30 \%$ in 2005.

of 371.8 Pg C with a range of 362.4-376.5 Pg C). Modeled SOC in the boreal region took a median value of 110.8 Pg C with an IQR of 238.6 Pg C, consistent with observed data sets (mean of $113.3 \mathrm{Pg} \mathrm{C}$ with a range of 72.6-159.3 Pg C). Largest IQR of SOC in temperate region rather than in tropical and boreal regions was found, which indicate that large uncertainties in SOC of TBMs come from the temperate region.

\section{Discussion}

\subsection{Large Modeled Differences of Projected Future $\triangle S O C$}

Previous studies reported that a large range of initial or present-day SOC stocks were simulated by TBMs when they are coupled to climate model or run offline with the same climate forcing, going from 510 to 3,040 Pg C for 11 TBMs part of the CMIP5 ESMs (Todd-Brown et al., 2014) and from 425 to 2,111 Pg C among 10 offline TBMs in MsTMIP (Tian, Lu, et al., 2015). The CMIP5 models have biases in climate causing a bias of SOC, whereas the MsTMIP models only covered the historical period. In this study, historical and future projections of SOC with bias-adjusted climate and harmonized LUC forcing make it possible to examine $\triangle S O C$ driven by climate and LUC continuously for the historical period and the future.

We found that simulated global $\triangle S O C$ during the historical period (1861-2005) is a small increase, with a median value of 16.51 Pg C and a large range going from -81.3 to $88.8 \mathrm{Pg} \mathrm{C}$ (Table 2). This result from ISIMIP2b models is higher but comparable to MsTMIP that gave a median change of 3.39 Pg C from 1901 to 2010 , with a range of -70.2 to $85.9 \mathrm{Pg} \mathrm{C}$ (Tian, Lu, et al., 2015). Besides, our results show that most models project a future global SOC increase under the RCP 2.6 scenario (2005-2099; median value of $31.91 \mathrm{Pg} \mathrm{C}$ ) and under RCP 6.0 scenario (2005-2099; median value of $31.40 \mathrm{Pg} \mathrm{C}$ ). The global $\triangle S O C$ reported here is slightly 
higher but narrower than estimates from 11 ESMs presented in Todd-Brown et al. (2014) for the RCP 8.5 scenario, with a median increase of $15 \mathrm{Pg} \mathrm{C}$ and a range of -72 to $253 \mathrm{Pg} \mathrm{C}$.

Our results showed that uncertainties in $\triangle S O C$ were more attributed to structural differences between TBMs rather than to differences in GCMs (Figure 3). The ISMIP2b TBMs used the same protocol for spin-up, the same input data, LUC data, and climate forcing (Frieler et al., 2017; Tian, Lu, et al., 2015). Yet even if GCM bias adjustment was applied to match observed mean climate period 1960-1990 (Hempel et al., 2013) the different GCM forcing data have distinct climate variability for the historical period, and differences in future climate as well (Table S6) due to different GCMs climate sensitivities. Furthermore, the vegetation distribution was not harmonized between models, which introduced inconsistencies in the simulation of SOC between models.

\subsection{Uncertainties in Constrained $\triangle S O C$ for Dominated Area by Natural Vegetation}

It is known that future $\triangle S O C$ is sensitive to climate via both changes in soil input and decomposition (Carvalhais et al., 2014; Jones et al., 2005; Todd-Brown et al., 2013; Yan et al., 2014). Our results showed that soil input changes explain most of the simulated $\triangle S O C$ across the ISIMIP2b TBMs at global scale and also in different regions, the rest of variation being explained by the interaction between initial soil carbon stocks, decomposition rate, and changes in soil inputs for RCP 6.0 (Figures 4-7). Such results are consistent with previous study with 11 ESMs from CMIP5 (Todd-Brown et al., 2014).

We showed that the success of using observed recent NPP trend as a constraint for future $\triangle S O C$ over natural vegetation depends on the choice of the GCM. Our proposed emergent constrained worked well with the HadGEM2-ES in the boreal region and with all GCMs in the temperate region. It also works for constraining global $\triangle S O C$, with a given GCM, but provides diverging results between different GCMs. This is because GCMs differ in their regional patterns of climate change, with possible compensating effects of climate change on $\triangle S O C$ between different regions, for instance, decreased rainfall reducing input and increased temperature increasing them. The failure to reliably constrain $\triangle S O C$ at the regional scale for the tropical and boreal regions with most GCMs may be attributed to the uncertainties in observed NPP trends and the weak relationships established for the emergent constraint when it is applied at regional scale. The NPP trend in the P model is stronger than in the BESS model (Table S2), possibly because nutrient limitations are not included in the P model (Jiang \& Ryu, 2016; Wang et al., 2017). Previous studies indicated that NPP is strongly limited by N availability in many ecosystems, especially in boreal forests (Hickler et al., 2015). In addition, observed NPP trend based on satellite observation includes implicitly the management of forest and pasture, which is ignored in ISIMIP2b models. Due to the small number of TBMs used to establish emergent constraint relationships, the $R^{2}$ of linear regressions between NPP trend and future input change (0.27-0.51) was low in the tropical region (Figure 5). It should be noted that the effective constrained on $\triangle S O C$ is based on a significant relationship between $\triangle S O C$ and changes in soil input. We expect that applying the same approach to larger ensembles of models is likely a larger spread and a better-defined relationship to constrain SOC changes.

\subsection{Uncertainties in Constrained $\Delta s o c$ for Dominated Area by Cropland}

We showed that soil carbon losses in LUC-dominated regions are mostly caused by conversion of natural vegetation to cropland, consistent with previous studies (Deng et al., 2016; Don et al., 2011; Guo \& Gifford, 2002; Li et al., 2018; Poeplau et al., 2011; Wei et al., 2014). For example, the meta-analysis by Guo and Gifford (2002) found a SOC decline of $42 \%$ and 59\% after LUC from forest to cropland and pasture to cropland. Models that do not reduce soil C input from harvested cropland NPP tend to underestimate SOC reductions from cropland expansion $(-2.64 \pm 8.43$ vs. $-1.03 \pm 19.94 \mathrm{Pg} \mathrm{C}$ for modeled vs. estimated

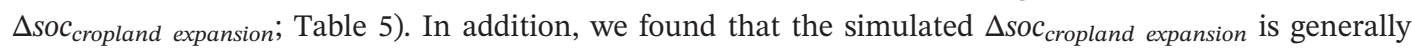

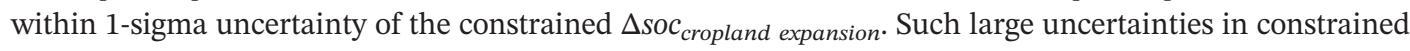

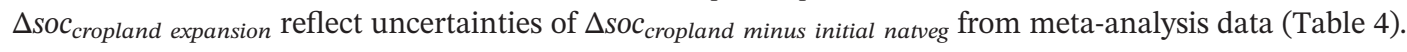

Anthropogenic LUCs have resulted into about $50 \times 10^{6} \mathrm{~km}^{2}$ being used for cropland (about $12 \%$ of the total ice-free land area) and pasture (about 26\% of the total ice-free land area) (Foley et al., 2007, 2011). In the ISIMIP2b simulations, the harmonized area of cropland and pasture used as a forcing for past simulations increases by 8.7 and $20.0 \times 10^{6} \mathrm{~km}^{2}$ in the historical run (1861-2005) (Figures S12 and S13 and Table S7). For future RCP 2.6 and RCP 6.0 simulations (2005-2099), the harmonized area of cropland increases by 
4.3 and $0.7 \times 10^{6} \mathrm{~km}^{2}$, while the harmonized area of pasture decreases by 7.3 and $1.1 \times 10^{6} \mathrm{~km}^{2}$ (see Table S7).

Based on constrained $\Delta s o c_{\text {cropland expansion }}$ and future cropland expansion area, we tentatively suggest that future cropland expansion will result in carbon losses in most of regions (Table 5 and Figures S12 and S13). These results are consistent with previous studies reporting that land use will be an important driver of SOC in the future (Lozano-García et al., 2017; Molotoks et al., 2018). The degree of cropland expansion results in SOC change partially dependent upon the land management practices (i.e., harvest), soil condition (e.g., soil properties and soil type), and climate condition. Crop harvest for bioenergy production can reduce inputs to the soil and diminish soil fertility (Powlson et al., 2012). In general, SOC decreases when land use conversion is from forest to cropland but varies with forest type and cultivation stage (Wei et al., 2014). The conversion from natural vegetation to cropland breaks down the aggregate structure that physically protects SOC from microbial decomposition (Wei et al., 2013), leading to more available SOC for microbial attacks. Future increased temperature will result in greater SOC losses by increasing decomposition rate but also cause a positive feedback between SOC mineralization and global warming.

Models handled in different ways the harvest of crop biomass, a process that reduces litter C inputs to soils over cropland grid cells, with only four models (i.e., LPJmL, VISIT, ORCHIDEE-MICT, and DLEM) excluding harvested carbon from inputs (Table S1) as it is the case in the real world. In LPJmL crop harvested carbon is added to a "harvest flux" variable at the time of harvest, and this flux is assumed to be lost as $\mathrm{CO}_{2}$ to the atmosphere. In ORCHIDEE-MICT, crop harvest is modeled as a daily removal of litter and reported as a separate annual emission to the atmosphere. In addition, ORCHIDEE-MICT takes into account the effect of tillage by increasing decomposition rate in cropland to mimic the fact that tillage increases soil oxygenation and thus accelerates the decomposition of SOC (Ciais et al., 2011; Gervois et al., 2008). In VISIT, a residual fraction of crop harvest returns to the soil as litter. In DLEM, harvested crop carbon enters a 1 year product pool that decomposes at a prescribed rate into atmospheric $\mathrm{CO}_{2}$ and does not return to soil. Part of the crop residue is further removed from the field due to management (e.g., fire; the value is set as 30\%), and the remaining $70 \%$ is allocated to litter pools (Zhang et al., 2018). Pasture grazing is also an important component of LUC affecting SOC. Only LPJmL includes pasture grazing management (Table 1) through $75 \%$ of leaf biomass being grazed when leaf biomass reaches threshold of $100 \mathrm{~g} \mathrm{C} \mathrm{m}^{-2}$ and emitted as $\mathrm{CO}_{2}$ to the atmosphere (Bondeau et al., 2007; Waha et al., 2012).

Previous studies have highlighted the importance of accounting for agricultural land and management (e.g., harvest, grazing, tillage, and residue management) in model simulations (Pugh et al., 2015). In this study, modeled SOC from cropland expansion showed large difference between models, which are related to different cropland management schemes and implies large uncertainty in future projections. Theoretically, crop harvest reduces carbon input into soil. However, Figures S5e and S5f show that the LUC may have limited effects on NPP simulations. The reduced SOC in agricultural land may be mainly driven by decreased litter return to the soil because of harvest and accelerated SOC decomposition because of tillage, rather than reduced NPP. In this study, four models (i.e., VISIT, LPJmL, ORCHIDEE-MICT, and DLEM) include cropland harvest in their parameterization. LPJmL, ORCHIDEE-MICT, and DLEM actually consider that harvested carbon is released as $\mathrm{CO}_{2}$ to the atmosphere. As a result, negative $\Delta$ soc $_{\text {cropland minus }}$ initial natveg was observed from those three models that do not allocate crop harvest to soil pools (Figure S3). However, the residual part of the harvest NPP of cropland from VISIT returns to field as litter, which

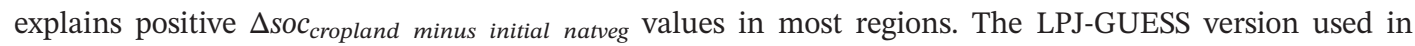
ISIMIP2b did not consider crop harvest. Therefore, how to treat crop harvest and the management of crop residue is a key source of uncertainty for modeling SOC changes from cropland expansion in the ISIMIP2b models. We recommend a better treatment of harvested crop carbon in TBMs, accounting for the harvest flux to leave the system rather than allocating harvests to SOC pools.

In addition, it is important to note that not all models have taken into account tillage process except for ORCHIDEE-MICT. ORCHIDEE-MICT considers the effect of tillage by increasing decomposition rate in cropland to mimic increased soil oxygenation and accelerated decomposition of SOC after tillage (Gervois et al., 2008). In general, tillage can improve the decomposition of crop residues by facilitating contact between plant tissue and soil aggregate surface (Bronick \& Lal, 2005) and increases the availability of nutrients for plant growth through distributing organic matter. In conjunction with this, the effectiveness of 
tillage on SOC in comparison to no tillage is controversial (Angers \& Eriksen-Hamel, 2008; Virto et al., 2012). Several studies observed an increase of soil organic matter and carbon with no tillage or conservation tillage (minimum tillage) in the top soil layer (Pinheiro et al., 2015; Powlson et al., 2012; Vogeler et al., 2009). However, such effect is partly or completely offset by greater SOC content in the deeper soil layers under conventional tillage (complete inversion of soil through plowing; Álvaro-Fuentes et al., 2013). These discrepancies are not surprising since tillage effects integrate a complex set of biological and environmental factors, such as the management practices (e.g., fertilization; Gregorich et al., 2005), crop performance (e.g., cropping intensity and crop types; VandenBygaart et al., 2003), and climate conditions (e.g., soil temperature and soil moisture; Snyder et al., 2009). In the TBMs used here, the effect of tillage is either represented as a scaling factor increasing the SOC decomposition rate in ORCHIDEE-MICT (Gervois et al., 2008) or ignored in other models. A newer version of LPJmL now incorporates two processes directly affected by tillage, including surface litter reduction from tillage management and decreased bulk soil density affecting soil hydrology (Lutz et al., 2019).

\subsection{How to Improve Emergent Constraints on Soil Carbon Changes}

The use of an emergent constraint to constrain an ensemble of model results requires (i) a strong regression relationship between the target variable to be constrained and the variable used to predict this target (e.g.,

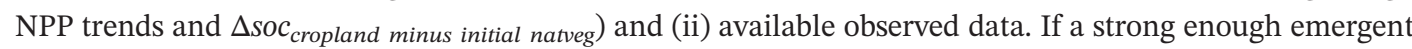
relationship can be established, then it can be confidently combined with observation to produce a constrained target variable. In our study, the hypothesis behind this two-step emergent constraint for SOC changes of natural vegetation is that future carbon input changes can be constrained from observation-based trends of past NPP. This hypothesis was verified, but observed trends of NPP were different between the two products considered. The hypothesis to constrain $\Delta s o c_{\text {cropland expansion }}$ is that this target variable is related to mean soc differences between cropland and historical natural vegetation. This hypoth-

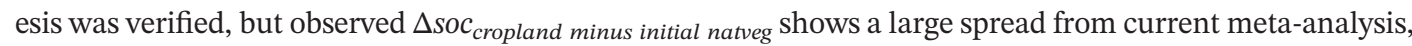
limiting the success of this approach. We recommend to pursue this approach but select meta-analysis data and use PFT-specific SOC output from models, instead of grid cell averages with cropland fraction above a threshold as it was done here because ISIMIP models did not report PFT-specific carbon variables.

\subsection{Limitations}

Despite developments in some models to incorporate agricultural management practices (Ciais et al., 2011; Ito \& Inatomi, 2012; Lutz et al., 2019; Pugh et al., 2015; Tian et al., 2010; Wu et al., 2016), some limitations still remain for projection of SOC relative to this driver in our set of ISIMIP model. Carbon storage in cropland is heavily dependent on management practices. Practices such as tillage, crop rotation, crop residue, and management are very important to soil carbon decomposition but are not included in all models. Moreover, the inclusion of nitrogen fertilizers was found to be a limiting factor in the amount of carbon stored (Drewniak et al., 2015). In this study, nitrogen effects on SOC are not considered in all the models (Table S1). In addition, the use of new varieties affecting the harvest index, productivity, and growing season duration with consequences on SOC inputs is not considered in the ISIMIP models. Further research is needed to management practices in models and their regional/historical changes to better model cropland soil carbon.

\section{Conclusion}

SOC changes have been significantly influenced by climate and LUC over the past century. Even though an increasing number of data sets are available to constrain future simulations, large differences between climate scenarios and TBMs remain, which implies large uncertainty of future projections. We show that uncertainties in future $\triangle S O C$ can be primarily attributed to the structural differences between TBMs rather than difference in GCMs. For RCP 2.6 LUC is the dominant driver of future $\triangle S O C$, while for RCP 6.0, the climate change effect dominates. Soil input changes explain most of variations in projected $\triangle S O C$ across the TBMs globally and in different climate regions. Applying an emergent constraint for $\triangle S O C$ to climate change under RCP 6.0, our results showed a reduction in constrained $\triangle S O C$ compared to original modeled ensembles for all GCMs in the temperate region and one GCM (i.e., HadGEM2-ES) globally and in the boreal region. In cropland-dominated areas, SOC will continue to diminish under RCP $2.6(-0.19 \pm 3.72 \mathrm{Pg} C)$ and RCP $6.0(-0.18 \pm 3.52 \mathrm{Pg} \mathrm{C})$ due to cropland expansion but with gains and losses compensating between 
regions. In cropland-dominated areas, the large spread in constrained $\Delta$ soc $_{\text {cropland expansion }}$ comes from uncertainties of observations. The idea of an emergent constraint approach purposefully reduced uncertainties in future projections of SOC. Although the uncertainties in constrain $\triangle S O C$ are still relatively high, as more accurate observation data and more model simulations become available, applying an emergent constraint approach to improve the accuracy of future $\triangle S O C$ projections is a promising research avenue. More importantly, understanding how SOC could be impacted by future climate change and LUCs can effectively help land managers and policymakers to develop appropriate land planning strategies.

\section{Data Availability Statement}

Model data from ISIMIP2b are publicly available online (https://esg.pik-potsdam.de/projects/isimip/). GPP products from P model are available from Stocker et al. (2019) (https://zenodo.org/record/1423484\#. XKNO8pj7Q2x). GPP products from BESS are publicly available from Jiang and Ryu (2016) (http://environment.snu.ac.kr/bess_flux/). The soil organic carbon density data from meta-analysis are available from Deng et al. (2016), Li et al. (2018), and Nyawira et al. (2016). HWSD data are available from FAO/IIASA/ISRIC/ ISSCAS/JRC (2012) (http://www.fao.org/soils-portal/soil-survey/soil-maps-and-databases/harmonizedworld-soil-database-v12/zh/), the NCSCD are available from Tarnocai et al. (2009) (https://bolin.su.se/ data/ncscd/), and the WISE30sec are available from Batjes (2016) (https://www.isric.org/explore/wisedatabases).

\section{Acknowledgments}

This work has been conducted under the framework of the Inter-Sectoral Impact Model Intercomparison Project Phase $2 b$ (ISIMIP2b) funded by the German Federal Ministry of Education and Research (Bundesministerium für Bildung und Forschung [BMBF], gran no. 01LS1711A). A. I. was supported by Climate Change Adaptation Research Program of National Institute for Environmental Studies (NIES), Japan. B. G. acknowledges the French government for funding under the Agence Nationale de la Recherche (ANR) "Investissements d'avenir" program with the reference CLAND ANR-16CONV-0003. C. P. O. R. acknowledges financial support from the German Federal Ministry of Education and Research (BMBF, grant no. 01LS1711A). The ORCHIDEE-MICT simulations of ISIMIP were performed using the HPC resources from Grand Équipement National De Calcul Intensif (GENCI) TGCC (grant no. 2019-A0010806820). This work was supported by ISIpedia JPI-Climate ERA4CS project.

\section{References}

Álvaro-Fuentes, J., Morell, F. J., Madejón, E., Lampurlanés, J., Arrúe, J. L., \& Cantero-Martínez, C. (2013). Soil biochemical properties in a semiarid Mediterranean agroecosystem as affected by long-term tillage and N fertilization. Soil and Tillage Research, 129, 69-74. https:// doi.org/10.1016/j.still.2013.01.005

Angers, D. A., \& Eriksen-Hamel, N. S. (2008). Full-inversion tillage and organic carbon distribution in soil profiles: A meta-analysis. Soil Science Society of America Journal, 72(5), 1370-1374. https://doi.org/10.2136/sssaj2007.0342

Batjes, N. H. (2016). Harmonized soil property values for broad-scale modelling (WISE30sec) with estimates of global soil carbon stocks. Geoderma, 47, 151-163. https://doi.org/10.1111/j.1365-2389.1996.tb01386.x

Bellamy, P. H., Loveland, P. J., Bradley, R. I., Lark, R. M., \& Kirk, G. J. (2005). Carbon losses from all soils across England and Wales 1978-2003. Nature, 74(3), 820-828. https://doi.org/10.2136/sssaj2009.0036

Bondeau, A., Smith, P. C., Zaehle, S., Schaphoff, S., Lucht, W., Cramer, W., et al. (2007). Modelling the role of agriculture for the 20th century global terrestrial carbon balance. Global Change Biology, 13(3), 679-706. https://doi.org/10.1111/j.1365-2486.2006.01305.x

Bronick, C. J., \& Lal, R. (2005). Manuring and rotation effects on soil organic carbon concentration for different aggregate size fractions on two soils in northeastern Ohio, USA. Soil and Tillage Research, 81(2), 239-252. https://doi.org/10.1016/j.still.2004.09.011

Carvalhais, N., Forkel, M., Khomik, M., Bellarby, J., Jung, M., Migliavacca, M., et al. (2014). Global covariation of carbon turnover times with climate in terrestrial ecosystems. Nature, 514, 213-217. https://doi.org/10.1038/nature13731

Ciais, P., Gervois, S., Vuichard, N., Piao, S. L., \& Viovy, N. (2011). Effects of land use change and management on the European cropland carbon balance. Global Change Biology, 17(1), 320-338. https://doi.org/10.1111/j.1365-2486.2010.02341.x

Ciais, P., Sabine, C., Bala, G., Bopp, L., Brovkin, V., Canadell, J., et al. (2014). Carbon and other biogeochemical cycles. In T. F. Stocker et al (Eds.), Climate change 2013: The physical science basis. Contribution of Working Group I to the Fifth Assessment Report of the Intergovernmental Panel on Climate Change (pp. 465-570). Cambridge, United Kingdom and New York, NY, USA: Cambridge University Press.

Cox, P. M., Pearson, D., Booth, B. B., Friedlingstein, P., Huntingford, C., Jones, C. D., \& Luke, C. M. (2013). Sensitivity of tropical carbon to climate change constrained by carbon dioxide variability. Nature, 494, 341-344. https://doi.org/10.1038/nature11882

De Kauwe, M. G., Keenan, T. F., Medlyn, B. E., Prentice, I. C., \& Terrer, C. (2016). Satellite based estimates underestimate the effect of CO fertilization on net primary productivity. Nature Climate Change, 6, 892-893. https://doi.org/10.1038/nclimate3105

Deng, L., Zhu, G.-Y., Tang, Z.-S., \& Shangguan, Z.-P. (2016). Global patterns of the effects of land-use changes on soil carbon stocks. Global Ecology and Conservation, 5, 127-138. https://doi.org/10.1016/j.gecco.2015.12.004

Doetterl, S., Stevens, A., Six, J., Merckx, R., van Oost, K., Casanova Pinto, M., et al. (2015). Soil carbon storage controlled by interactions between geochemistry and climate. Nature Geoscience, 8, 780-783. https://doi.org/10.1038/ngeo2516

Don, A., Schumacher, J., \& Freibauer, A. (2011). Impact of tropical land-use change on soil organic carbon stocks-A meta-analysis. Global Change Biology, 17(4), 1658-1670. https://doi.org/10.1111/j.1365-2486.2010.02336.x

Drewniak, B. A., Mishra, U., Song, J., Prell, J., \& Kotamarthi, V. R. (2015). Modeling the impact of agricultural land use and management on US carbon budgets. Biogeosciences, 12, 2119-2129. https://doi.org/10.5194/bg-12-2119-2015

FAO/IIASA/ISRIC/ISSCAS/JRC (2012). Harmonized World Soil Database (version 1.10), FAO, Rome, Italy and IIASA, Laxenburg, Austria.

Foley, J. A., Monfreda, C., Ramankutty, N., \& Zaks, D. (2007). Our share of the planetary pie. Proceedings of the National Academy of Sciences, 104(31), 12,585-12,586. https://doi.org/10.1073/pnas.0705190104

Foley, J. A., Ramankutty, N., Brauman, K. A., Cassidy, E. S., Gerber, J. S., Johnston, M., et al. (2011). Solutions for a cultivated planet. Nature, 478(7369), 337-342. https://doi.org/10.1038/nature10452

Frieler, K., Lange, S., Piontek, F., Reyer, C. P. O., Schewe, J., Warszawski, L., et al. (2017). Assessing the impacts of $1.5^{\circ} \mathrm{C}$ global warming-Simulation protocol of the Inter-Sectoral Impact Model Intercomparison Project (ISIMIP2b). Geoscientific Model Development, 10, 4321-4345. https://doi.org/10.5194/gmd-10-4321-2017

Gervois, S., Ciais, P., de Noblet-Ducoudré, N., Brisson, N., Vuichard, N., \& Viovy, N. (2008). Carbon and water balance of European croplands throughout the 20th century. Global Biogeochemical Cycles, 22, GB2022. https://doi.org/10.1029/2007GB003018 
Gregorich, E., Rochette, P., VandenBygaart, A., Angers, D. J. S., \& Research, T. (2005). Greenhouse gas contributions of agricultural soils and potential mitigation practices in Eastern Canada. Soil and Tillage Research, 83(1), 53-72. https://doi.org/10.1016/j. still.2005.02.009

Guimberteau, M., Zhu, D., Maignan, F., Huang, Y., Yue, C., Dantec-Nédélec, S., et al. (2018). ORCHIDEE-MICT (v8.4.1), a land surface model for the high latitudes: Model description and validation. Geoscientific Model Development, 11, 121-163. https://doi.org/10.5194/ gmd-11-121-2018

Guo, L. B., \& Gifford, R. M. (2002). Soil carbon stocks and land use change: A meta analysis. Global Change Biology, 8(4), 345-360. https:// doi.org/10.1046/j.1354-1013.2002.00486.x

Haberl, H., Erb, K. H., Krausmann, F., Gaube, V., Bondeau, A., Plutzar, C., et al. (2007). Quantifying and mapping the human appropriation of net primary production in earth's terrestrial ecosystems. Proceedings of the National Academy of Sciences, 104(31), 12,942-12,947. https://doi.org/10.1073/pnas.0704243104

Hall, A., Cox, P., Huntingford, C., \& Klein, S. (2019). Progressing emergent constraints on future climate change. Nature Climate Change, 9 , 269-278. https://doi.org/10.1038/s41558-019-0436-6

Hamdi, S., Moyano, F., Sall, S., Bernoux, M., \& Chevallier, T. (2013). Synthesis analysis of the temperature sensitivity of soil respiration from laboratory studies in relation to incubation methods and soil conditions. Soil Biology and Biochemistry, 58, 115-126. https://doi.org/ 10.1016/j.soilbio.2012.11.012

Hansis, E., Davis, S. J., \& Pongratz, J. (2015). Relevance of methodological choices for accounting of land use change carbon fluxes. Global Biogeochemical Cycles, 29, 1230-1246. https://doi.org/10.1002/2014GB004997

He, Y., Piao, S., Li, X., Chen, A., \& Qin, D. (2018). Global patterns of vegetation carbon use efficiency and their climate drivers deduced from MODIS satellite data and process-based models. Agricultural and Forest Meteorology, 256-257, 150-158. https://doi.org/10.1016/ j.agrformet.2018.03.009

Hempel, S., Frieler, K., Warszawski, L., Schewe, J., \& Piontek, F. (2013). A trend-preserving bias correction-The ISI-MIP approach. Earth System Dynamics, 4, 219-236. https://doi.org/10.5194/esd-4-219-2013

Hengl, T., Mendes de Jesus, J., Heuvelink, G. B. M., Ruiperez Gonzalez, M., Kilibarda, M., Blagotić, A., et al. (2017). SoilGrids250m: Global gridded soil information based on machine learning. PLOS ONE, 12, e0169748. https://doi.org/10.1371/journal.pone.0169748

Hickler, T., Rammig, A., \& Werner, C. (2015). Modelling $\mathrm{CO}_{2}$ impacts on forest productivity. Current Forestry Reports, 1, 69-80. https://doi. org/10.1007/s40725-015-0014-8

Houghton, R. A., \& Nassikas, A. A. (2017). Global and regional fluxes of carbon from land use and land cover change 1850-2015. Global Biogeochemical Cycles, 31, 456-472. https://doi.org/10.1002/2016GB005546

Ito, A., \& Inatomi, M. (2012). Water-use efficiency of the terrestrial biosphere: A model analysis focusing on interactions between the global carbon and water cycles. Journal of Hydrometeorology, 13(2), 681-694. https://doi.org/10.1175/jhm-d-10-05034.1

Jiang, C., \& Ryu, Y. (2016). Multi-scale evaluation of global gross primary productivity and evapotranspiration products derived from Breathing Earth System Simulator (BESS). Remote Sensing of Environment, 186, 528-547. https://doi.org/10.1016/j.rse.2016.08.030

Jones, C., McConnell, C., Coleman, K., Cox, P., Falloon, P., Jenkinson, D., \& Powlson, D. (2005). Global climate change and soil carbon stocks; predictions from two contrasting models for the turnover of organic carbon in soil. Global Change Biology, 11(1), 154-166. https:// doi.org/10.1111/j.1365-2486.2004.00885.x

Klein Goldewijk, K., Beusen, A., Doelman, J., \& Stehfest, E. J. E. S. S. D. (2017). New anthropogenic land use estimates for the Holocene: HYDE 3.2. Earth System Science Data, 9, 927-953. https://doi.org/10.5194/essd-9-927-2017

Kolby Smith, W., Cleveland, C. C., Reed, S. C., \& Running, S. W. (2014). Agricultural conversion without external water and nutrient inputs reduces terrestrial vegetation productivity. Geophysical Research Letters, 41, 449-455. https://doi.org/10.1002/2013GL058857

Kolby Smith, W., Reed, S. C., Cleveland, C. C., Ballantyne, A. P., Anderegg, W. R. L., Wieder, W. R., et al. (2015). Large divergence of satellite and Earth system model estimates of global terrestrial $\mathrm{CO}_{2}$ fertilization. Nature Climate Change, 6, 306-310. https://doi.org/ $10.1038 /$ nclimate2879

Koven, C. D., Chambers, J. Q., Georgiou, K., Knox, R., Negron-Juarez, R., Riley, W. J., et al. (2015). Controls on terrestrial carbon feedbacks by productivity versus turnover in the CMIP5 Earth System Models. Biogeosciences, 12, 5211-5228. https://doi.org/10.5194/ bg-12-5211-2015

Krausmann, F., Erb, K.-H., Gingrich, S., Lauk, C., \& Haberl, H. (2008). Global patterns of socioeconomic biomass flows in the year 2000: A comprehensive assessment of supply, consumption and constraints. Ecological Economics, 65(3), 471-487. https://doi.org/10.1016/ j.ecolecon.2007.07.012

Lange, S. (2016). EartH2Observe, WFDEI and ERA-Interim data Merged and Bias-corrected for ISIMIP (EWEMBI), GFZ Data Services, https://doi.org/10.5880/pik.2019.004

Li, W., Ciais, P., Guenet, B., Peng, S., Chang, J., Chaplot, V., et al. (2018). Temporal response of soil organic carbon after grassland-related land-use change. Global Change Biology, 24, 4731-4746. https://doi.org/10.1111/gcb.14328

Li, W., Ciais, P., Peng, S., Yue, C., Wang, Y., Thurner, M., et al. (2017). Land-use and land-cover change carbon emissions between 1901 and 2012 constrained by biomass observations. Biogeosciences, 14, 5053-5067. https://doi.org/10.5194/bg-14-5053-2017

Lian, X., Piao, S., Huntingford, C., Li, Y., Zeng, Z., Wang, X., et al. (2018). Partitioning global land evapotranspiration using CMIP5 models constrained by observations. Nature Climate Change, 8, 640-646. https://doi.org/10.1038/s41558-018-0207-9

Liu, S., Wei, Y., Post, W. M., Cook, R. B., Schaefer, K., \& Thornton, M. M. (2013). The Unified North American Soil Map and its implication on the soil organic carbon stock in North America. Biogeosciences, 10, 2915-2930. https://doi.org/10.5194/bg-10-2915-2013

Lozano-García, B., Muñoz-Rojas, M., \& Parras-Alcántara, L. (2017). Climate and land use changes effects on soil organic carbon stocks in a Mediterranean semi-natural area. Science of the Total Environment, 579, 1249-1259. https://doi.org/10.1016/j.scitotenv.2016.11.111

Luo, Y., Ahlström, A., Allison, S. D., Batjes, N. H., Brovkin, V., Carvalhais, N., et al. (2016). Toward more realistic projections of soil carbon dynamics by Earth system models. Global Biogeochemical Cycles, 30, 40-56. https://doi.org/10.1002/2015GB005239

Lutz, F., Herzfeld, T., Heinke, J., Rolinski, S., Schaphoff, S., von Bloh, W., et al. (2019). Simulating the effect of tillage practices with the global ecosystem model LPJmL (version 5.0-tillage). Geoscientific Model Development, 12, 2419-2440. https://doi.org/10.5194/gmd-122419-2019

Meinshausen, M., Smith, S. J., Calvin, K., Daniel, J. S., Kainuma, M. L. T., Lamarque, J. F., et al. (2011). The RCP greenhouse gas concentrations and their extensions from 1765 to 2300. Climatic Change, 109(1-2), 213-241. https://doi.org/10.1007/s10584-0110156-Z

Molotoks, A., Stehfest, E., Doelman, J., Albanito, F., Fitton, N., Dawson, T. P., \& Smith, P. (2018). Global projections of future cropland expansion to 2050 and direct impacts on biodiversity and carbon storage. Global Change Biology, 24, 5895-5908. https://doi.org/10.1111/ gcb.14459 
Monfreda, C., Ramankutty, N., \& Foley, J. A. (2008). Farming the planet: 2. Geographic distribution of crop areas, yields, physiological types, and net primary production in the year 2000. Global Biogeochemical Cycles, 22, GB1022. https://doi.org/10.1029/2007GB002947

Müller, C., \& Robertson, R. D. (2014). Projecting future crop productivity for global economic modeling. Agricultural Economics, 45, 37-50. https://doi.org/10.1111/agec.12088

Neumann, M., \& Smith, P. (2018). Carbon uptake by European agricultural land is variable, and in many regions could be increased: Evidence from remote sensing, yield statistics and models of potential productivity. The Science of the Total Environment, 643, 902-911. https://doi.org/10.1016/j.scitotenv.2018.06.268

Nishina, K., Ito, A., Beerling, D. J., Cadule, P., Ciais, P., Clark, D. B., et al. (2014). Quantifying uncertainties in soil carbon responses to changes in global mean temperature and precipitation. Earth System Dynamics, 5, 197-209. https://doi.org/10.5194/esd-5-197-2014

Nyawira, S. S., Nabel, J. E. M. S., Don, A., Brovkin, V., \& Pongratz, J. (2016). Soil carbon response to land-use change: Evaluation of a global vegetation model using observational meta-analyses. Biogeosciences, 13, 5661-5675. https://doi.org/10.5194/bg-13-5661-2016

Peng, S., Ciais, P., Maignan, F., Li, W., Chang, J., Wang, T., \& Yue, C. (2017). Sensitivity of land use change emission estimates to historical land use and land cover mapping. Global Biogeochemical Cycles, 31, 626-643. https://doi.org/10.1002/2015GB005360

Pinheiro, É. F. M., de Campos, D. V. B., de Carvalho Balieiro, F., dos Anjos, L. H. C., \& Pereira, M. G. (2015). Tillage systems effects on soil carbon stock and physical fractions of soil organic matter. Agricultural Systems, 132, 35-39. https://doi.org/10.1016/j.agsy.2014.08.008

Poeplau, C., Don, A., Vesterdal, L., Leifeld, J., Van Wesemael, B. A. S., Schumacher, J., \& Gensior, A. (2011). Temporal dynamics of soil organic carbon after land-use change in the temperate zone-Carbon response functions as a model approach. Global Change Biology, 17(7), 2415-2427. https://doi.org/10.1111/j.1365-2486.2011.02408.x

Popp, A., Calvin, K., Fujimori, S., Havlik, P., Humpenöder, F., Stehfest, E., et al. (2017). Land-use futures in the shared socio-economic pathways. Global Environmental Change, 42, 331-345. https://doi.org/10.1016/j.gloenvcha.2016.10.002

Popp, A., Humpenöder, F., Weindl, I., Bodirsky, B. L., Bonsch, M., Lotze-Campen, H., et al. (2014). Land-use protection for climate change mitigation. Nature Climate Change, 4, 1095-1098. https://doi.org/10.1038/nclimate2444

Post, W. M., \& Kwon, K. C. (2000). Soil carbon sequestration and land-use change: Processes and potential. Global Change Biology, 6(3), 317-327. https://doi.org/10.1046/j.1365-2486.2000.00308.x

Powlson, D. S., Bhogal, A., Chambers, B. J., Coleman, K., Macdonald, A. J., Goulding, K. W. T., \& Whitmore, A. P. (2012). The potential to increase soil carbon stocks through reduced tillage or organic material additions in England and Wales: A case study. Agriculture, Ecosystems \& Environment, 146(1), 23-33. https://doi.org/10.1016/j.agee.2011.10.004

Pugh, T. A. M., Arneth, A., Olin, S., Ahlström, A., Bayer, A. D., Klein Goldewijk, K., et al. (2015). Simulated carbon emissions from land-use change are substantially enhanced by accounting for agricultural management. Environmental Research Letters, 10, 124008. https://doi. org/10.1088/1748-9326/10/12/124008

Ryu, Y., Baldocchi, D. D., Kobayashi, H., van Ingen, C., Li, J., Black, T. A., et al. (2011). Integration of MODIS land and atmosphere products with a coupled-process model to estimate gross primary productivity and evapotranspiration from $1 \mathrm{~km}$ to global scales. Global Biogeochemical Cycles, 25, GB4017. https://doi.org/10.1029/2011GB004053

Sanderman, J., Hengl, T., \& Fiske, G. J. (2017). Soil carbon debt of 12,000 years of human land use. Proceedings of the National Academy of Sciences of the United States of America, 114, 9575-9580. https://doi.org/10.1073/pnas.1706103114

Smith, B., Wårlind, D., Arneth, A., Hickler, T., Leadley, P., Siltberg, J., \& Zaehle, S. (2014). Implications of incorporating N cycling and N limitations on primary production in an individual-based dynamic vegetation model. Biogeosciences, 25, 3334-3353. https://doi.org/ $10.1111 /$ gcb. 14677

Snyder, C. S., Bruulsema, T. W., Jensen, T. L., \& Fixen, P. E. (2009). Review of greenhouse gas emissions from crop production systems and fertilizer management effects. Agriculture, Ecosystems \& Environment, 10(8), 1759-1789. https://doi.org/10.1029/2018MS001277

Stegehuis, A. I., Teuling, A. J., Ciais, P., Vautard, R., \& Jung, M. (2013). Future European temperature change uncertainties reduced by using land heat flux observations. Geophysical Research Letters, 40, 2242-2245. https://doi.org/10.1002/grl.50404

Stevanović, M., Popp, A., Lotze-Campen, H., Dietrich, J. P., Müller, C., Bonsch, M., et al. (2016). The impact of high-end climate change on agricultural welfare. Science Advances, 2, e1501452. https://doi.org/10.1126/sciadv.1501452

Stocker, B. D., Zscheischler, J., Keenan, T. F., Prentice, I. C., Seneviratne, S. I., \& Peñuelas, J. (2019). Drought impacts on terrestrial primary production underestimated by satellite monitoring. Nature Geoscience, 12, 264-270. https://doi.org/10.1038/s41561-019-0318-6

Tarnocai, C., Canadell, J. G., Schuur, E. A. G., Kuhry, P., Mazhitova, G., \& Zimov, S. (2009). Soil organic carbon pools in the northern circumpolar permafrost region. Global Biogeochemical Cycles, 23, GB2023. https://doi.org/10.1029/2008GB003327

Tian, H., Chen, G., Liu, M., Zhang, C., Sun, G., Lu, C., et al. (2010). Model estimates of net primary productivity, evapotranspiration, and water use efficiency in the terrestrial ecosystems of the southern United States during 1895-2007. Forest Ecology and Management, 259(7), 1311-1327. https://doi.org/10.1016/j.foreco.2009.10.009

Tian, H., Chen, G., Lu, C., Xu, X., Hayes, D. J., Ren, W., et al. (2015). North American terrestrial $\mathrm{CO}_{2}$ uptake largely offset by $\mathrm{CH}_{4}$ and $\mathrm{N}_{2} \mathrm{O}$ emissions: Toward a full accounting of the greenhouse gas budget. Climatic Change, 129, 413-426. https://doi.org/10.1007/s10584-014$1072-9$

Tian, H., Lu, C., Yang, J., Banger, K., Huntzinger, D. N., Schwalm, C. R., et al. (2015). Global patterns and controls of soil organic carbon dynamics as simulated by multiple terrestrial biosphere models: Current status and future directions. Global Biogeochemical Cycles, 29, 775-792. https://doi.org/10.1002/2014GB005021

Todd-Brown, K. E. O., Randerson, J. T., Hopkins, F., Arora, V., Hajima, T., Jones, C., et al. (2014). Changes in soil organic carbon storage predicted by Earth system models during the 21st century. Biogeosciences, 11, 2341-2356. https://doi.org/10.5194/bg-11-2341-2014

Todd-Brown, K. E. O., Randerson, J. T., Post, W. M., Hoffman, F. M., Tarnocai, C., Schuur, E. A. G., \& Allison, S. D. (2013). Causes of variation in soil carbon simulations from CMIP5 Earth system models and comparison with observations. Biogeosciences, 10, $1717-1736$. https://doi.org/10.5194/bg-10-1717-2013

VandenBygaart, A., Gregorich, E., \& Angers, D. J. C. J. O. S. S. (2003). Influence of agricultural management on soil organic carbon: A compendium and assessment of Canadian studies. Canadian Journal of Soil Science, 83(4), 363-380. https://doi.org/10.4141/S03-009

Virto, I., Barré, P., Burlot, A., \& Chenu, C. (2012). Carbon input differences as the main factor explaining the variability in soil organic C storage in no-tilled compared to inversion tilled agrosystems. Biogeochemistry, 108(1-3), 17-26. https://doi.org/10.1007/s10533-0119600-4

Vogeler, I., Rogasik, J., Funder, U., Panten, K., \& Schnug, E. (2009). Effect of tillage systems and P-fertilization on soil physical and chemical properties, crop yield and nutrient uptake. Soil and Tillage Research, 103(1), 137-143. https://doi.org/10.1016/ j.still.2008.10.004

Waha, K., van Bussel, L. G. J., Müller, C., \& Bondeau, A. (2012). Climate-driven simulation of global crop sowing dates. Global Ecology and Biogeography, 21, 247-259. https://doi.org/10.1111/j.1466-8238.2011.00678 
Wang, H., Prentice, I. C., Keenan, T. F., Davis, T. W., Wright, I. J., Cornwell, W. K., et al. (2017). Towards a universal model for carbon dioxide uptake by plants. Nature Plants, 3, 734-741. https://doi.org/10.1038/s41477-017-0006-8

Wei, X., Shao, M., Gale, W., \& Li, L. (2014). Global pattern of soil carbon losses due to the conversion of forests to agricultural land. Scientific Reports, 4, 4062. https://doi.org/10.1038/srep04062

Wei, X., Shao, M., Gale, W. J., Zhang, X., \& Li, L. (2013). Dynamics of aggregate-associated organic carbon following conversion of forest to cropland. Soil Biology and Biochemistry, 57, 876-883. https://doi.org/10.1016/j.soilbio.2012.10.020

Wenzel, S., Cox, P. M., Eyring, V., \& Friedlingstein, P. (2016). Projected land photosynthesis constrained by changes in the seasonal cycle of atmospheric $\mathrm{CO}_{2}$. Nature, 538, 499-501. https://doi.org/10.1038/nature19772

Wu, D., Piao, S., Liu, Y., Ciais, P., \& Yao, Y. (2018). Evaluation of CMIP5 Earth system models for the spatial patterns of biomass and soil carbon turnover times and their linkage with climate. Journal of Climate, 31, 5947-5960. https://doi.org/10.1175/JCLI-D-17-0380.1

Wu, X., Vuichard, N., Ciais, P., Viovy, N., de Noblet-Ducoudré, N., Wang, X., et al. (2016). ORCHIDEE-CROP (v0), a new process-based agro-land surface model: Model description and evaluation over Europe. Geoscientific Model Development, 9, 857-873. https://doi.org/ 10.5194/gmd-9-857-2016

Xiao, J., Davis, K. J., Urban, N. M., \& Keller, K. (2014). Uncertainty in model parameters and regional carbon fluxes: A model-data fusion approach. Agricultural and Forest Meteorology, 189-190, 175-186. https://doi.org/10.1016/j.agrformet.2014.01.022

Yan, Y., Luo, Y., Zhou, X., \& Chen, J. (2014). Sources of variation in simulated ecosystem carbon storage capacity from the 5th Climate Model Intercomparison Project (CMIP5). Tellus Series B: Chemical and Physical Meteorology, 66, 22568. https://doi.org/10.3402/tellusb. v66.22568

Zhang, J., Tian, H., Yang, J., \& Pan, S. (2018). Improving representation of crop growth and yield in the dynamic land ecosystem model and its application to China. Journal of Advances in Modeling Earth Systems, 10, 1680-1707. https://doi.org/10.1029/2017MS001253

Zhao, C., Piao, S., Wang, X., Huang, Y., Ciais, P., Elliott, J., et al. (2016). Plausible rice yield losses under future climate warming. Nature Plants, 3, 16202. https://doi.org/10.1038/nplants.2016.202

Zhao, M., \& Running, S. W. (2010). Drought-induced reduction in global terrestrial net primary production from 2000 through 2009. Science, 329(5994), 940-943. https://doi.org/10.1126/science.1192666 